\title{
O FEDERALISMO FISCAL BRASILEIRO E SUAS LIMITAÇÕES: ESTUDO DO FPM E A EQUALIZAÇÃO DAS RECEITAS PER CAPITA DOS MUNICÍPIOS DOS ESTADOS DO PARÁ E MINAS GERAIS NO ANO DE 2017
}

Artur Baker $^{1}$

\section{INTRODUÇÃO}

As formas de organização de governo despertam muitas questões a respeito dos aspectos de descentralização ou centralização e qual a melhor maneira de buscar-se eficiência, eficácia organizacional e condições básicas de equalização fiscal. Dentro deste espectro, as federações se caracterizam por ser um modelo de gestão que procura tais objetivos por meio da descentralização dos seus governos, os quais dotam entes subnacionais de certa autonomia na tomada de decisões. $O$ federalismo implica, também, uma certa distribuição das relações de poder sob o ponto de vista territorial, sendo que condicionantes econômicos, culturais, linguísticos, influenciam na partição federativa e na ordem de interação entre os diferentes entes subnacionais e a união federativa (ANDERSON, 2009; REZENDE, 2001; STIGLITZ, 2000).

Um dos principais problemas nas federações do mundo está na divisão das competências tributárias e na divisão das receitas de tributos entre os entes federados. Levandose aspectos de eficiência econômica, certos impostos necessitam que sua arrecadação seja feita em nível nacional, para se evitar externalidades, má alocação de recursos dentro do território da federação, uniformidade e progressividade na tributação, entre outros (OATES, 1999; NUN, 2011). Contudo, em uma federação, os encargos são distribuídos entre todos os entes federados, e as receitas advindas das bases tributárias de impostos regionais não são suficientes para cobrir seus gastos, necessitando de complementação de suas receitas através das transferências intergovernamentais.

Tais transferências têm como objetivo complementar os orçamentos dos entes subnacionais, estas podem ter caráter devolutivos, condicionantes ou redistributivos (PRADO, 2006a; KHAIR, 2013). O primeiro se caracteriza por representar a capacidade fiscal da jurisdição subnacional; o segundo vincula os seus recursos a setores específicos em que o governo federal possui interesses; e o terceiro possui o intuito de mitigar as disparidades existentes entre as regiões do país, objetivando uma harmonia na provisão de bens e serviços públicos em todos os entes da federação.

As transferências redistributivas, no Brasil, tomam forma com os fundos de participação de estados e municípios (FPE e FPM). Estes foram criados em 1966 e reformulados na CF/88, e

\footnotetext{
1 Economista formado pela Universidade Federal do Pará, mestrando no CEDEPLAR/UFMG.
} 
seus critérios pouco diferiram desde então, além das participações de cada estado estarem congeladas desde início dos anos 1990. Já que esses parâmetros não foram renovados, não observaram e, portanto, não acompanharam as dinâmicas ocorridas nas economias dos entes federados e nas suas capacidades de gerar receitas. Prado (2006b) coloca que os critérios destes fundos, ao não levarem em consideração as demais receitas dos entes federados, caracterizam-se apenas como fluxos redistributivos, não alcançando de forma satisfatória a equalização da capacidade de gasto per capita entre os estados e municípios do Brasil, o que implica desconsiderar as desigualdades econômicas regionais e locais, principalmente considerando as profundas diferenças regionais e a concentração de cadeias produtivas mais longas e, portanto, tributariamente de maiores retornos localizadas no sudeste brasileiro.

Desta forma, urge a discussão acerca da eficiência dos critérios utilizados na distribuição dos montantes e se estes alcançam seus objetivos de diminuir as diferenças entre os orçamentos fiscais dos entes federados. Assim, este trabalho foca-se nos critérios do FPM e analisa de que forma os recursos de tal fundo complementam os orçamentos dos municípios de dois estados, Pará e Minas Gerais no ano de 2017, localizados especificamente nas regiões Norte (periférica) e Sudeste (desenvolvida). A partir do colocado por Prado (2006a; 2006b), analisar-se-á as demais fontes de receita dos municípios e, após contabilizá-las, verificar de que maneira os montantes impactam nas receitas municipais de estados que se encontram em regiões de diferentes níveis de desenvolvimento.

Os dados utilizados para fazer a comparação são obtidos no site da Secretaria do Tesouro Nacional (STN), tendo sido utilizado o ano de 2017 por conta da proximidade temporal e pela maior disponibilidade de dados. A metodologia utilizada consiste na investigação dos níveis de equidade que o FPM proporciona aos municípios dos estados do Pará e Minas Gerais. Baseado no aporte analítico desenvolvido por Prado (2006b), busca-se averiguar quais as principais fontes de financiamento dos municípios e como estas se comportam a partir de faixas populacionais, critério este preponderante na partilha de recursos do FPM. A abordagem per capita é utilizada em relação as fontes de recurso estudadas por ser um indicador das demandas de bens e serviços dos municípios. Após tal análise, compara-se os resultados obtidos nos dois estados e discute-se acerca das desigualdades entre as unidades federativas e de que forma os montantes do fundo contribuem, ou não, na convergência de receitas fiscais de localidades mais pobres em direção aos níveis de receitas das localidades mais abastadas.

Justifica-se 0 estudo e sua relevância por dois aspectos que consideramos centrais: i) primeiramente, a análise federativa num cenário econômico e político brasileiro no qual se colocam enormes interrogações no horizonte quanto às condições de gestão do atual pacto 
federativo brasileiro (KHAIR, 2013; TRINDADE\&OLIVEIRA, 2013; OLIVEIRA, 2012); ii) a análise comparativa possibilita o entendimento mais profundo dos impactos e condições de gestão dos recursos, algo necessário para se pensar o aperfeiçoamento dos Fundos de Transferência.

Os estados supracitados encontram-se em regiões de distintos níveis de desenvolvimento, além de diferentes características demográficas e populacionais. No entanto, eles possuem certa semelhança, uma vez que são estados que têm como papel importante a atividade mineradora nas suas economias. Assim, além desta introdução, na seção seguinte caracteriza-se os tipos de transferências intergovernamentais, e diferencia-se os fluxos redistributivos e sistemas de equalização. Já na terceira seção é apresentado de forma sintética os critérios de partilha do FPM e os métodos utilizados. Na quarta seção, evidencia-se a análise das receitas dos municípios de Pará e Minas Gerais no ano de 2017, discutindo-se acerca das principais fontes de financiamento e de que forma os recursos do FPM complementam os orçamentos municipais. Por fim, as considerações finais encerram o trabalho.

\section{TRANSFERÊNCIAS INTERGOVERNAMENTAIS}

As transferências intergovernamentais se caracterizam pela distribuição de recursos do governo central para os entes de nível inferior. Tais transferências derivam do fato de os governos subnacionais não possuírem a capacidade de gerar receitas próprias em um volume suficiente para financiar todos os encargos por eles assumidos. A essa diferença dá-se o nome de brecha vertical, que é a diferença entre o gasto total das jurisdições e o nível de arrecadação autônoma que a mesma consegue gerar.

\subsection{Brecha Vertical e Tipos de Transferências}

Prado (2006a) explica a brecha vertical como resultado da necessidade de certos impostos serem instituídos do ponto de vista federal, para evitar ineficiências e distorções alocativas de investimentos no espaço nacional, na utilização como instrumento federal de diminuição das diferenças regionais, e pela interferência do governo central na promoção de áreas específicas de interesse comum.

A figura 1 ilustra o conceito de brecha vertical, a qual demonstra que as receitas oriundas das bases tributárias subnacionais são insuficientes para cobrir seus encargos em uma federação descentralizada, em que bens e serviços são providos por tais entes. Dessa forma, as transferências dos governos superiores explicam-se na necessidade de complementar as receitas subnacionais a fim de prover volume suficiente a cobrir seus encargos. 
Figura 1 - Exemplo de Brecha Vertical - R\$

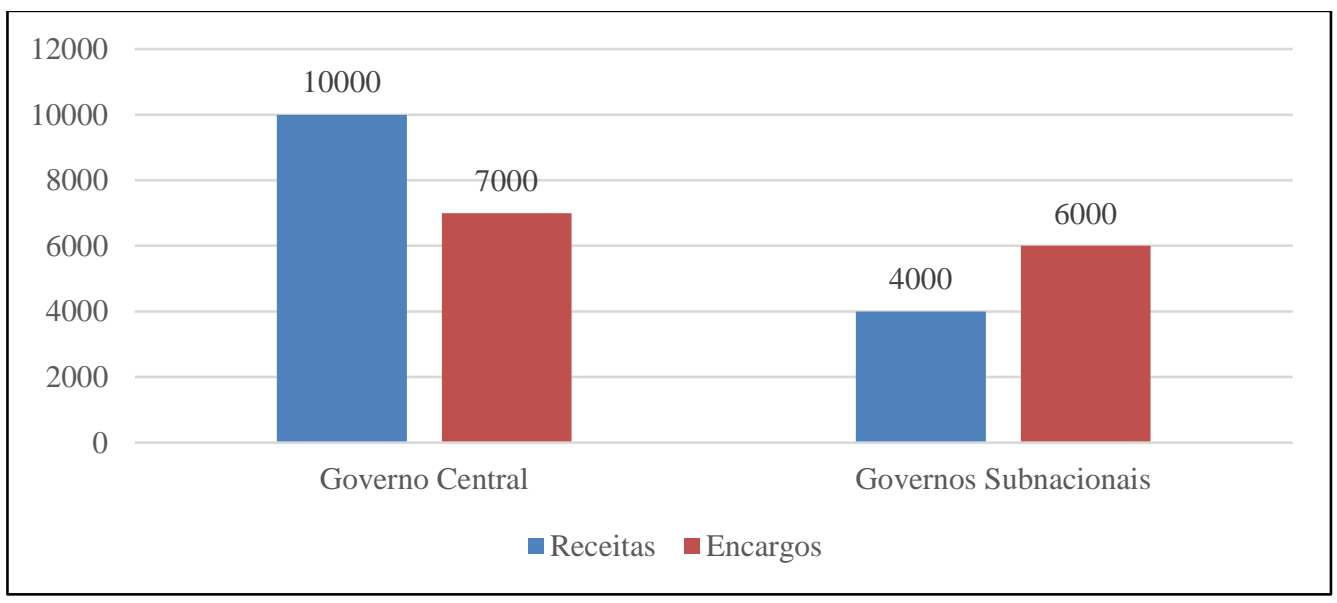

Fonte: Elaboração Própria.

Para atingir tais objetivos o governo federal possui transferências com diferentes características. As transferências devolutivas caracterizam-se pela receita compartilhada se dar por derivação, ou seja, a receita dispensada corresponde ao que foi recolhido em cada jurisdição. Desta forma, tal transferência relaciona-se com o valor adicionado e com o tamanho da base de exploração do imposto, não tendo nenhum papel na mitigação de diferenças regionais. O estabelecimento de competência legislativas, ou até mesmo administrativas, do ponto de vista central, decorre de custos elevados no processo de arrecadação ou de necessidade de uniformidade do imposto em toda a federação, não interferindo na alocação de recursos e corrigindo possíveis externalidades.

Já as transferências que possuem papel redistributivo, têm por intuito não apenas refletir a capacidade econômica de cada ente governamental, mas sim de ajustar desequilíbrios horizontais a fim de diminuir as diferenças regionais, proporcionando 0 acesso a serviços públicos comuns a todas as jurisdições com a mesma qualidade e sem custos adicionais. Cabe ao governo central, o estabelecimento de critérios eficientes que traduzam essas distinções de capacidades econômicas para que a distribuição de recursos alcance o seu objetivo. Tal ocorrência de desequilíbrios horizontais é demonstrada a seguir na figura 2, em que entes subnacionais de mesmo nível possuem receitas díspares de acordo com suas capacidades fiscais, podendo ser suficientes ou não para cobrir seus encargos, mostrando a necessidade de parâmetros que internalizem tais discrepâncias na hora da partilha dos recursos redistributivos. 
Figura 2 - Exemplos de Desequilíbrios Horizontais - R\$

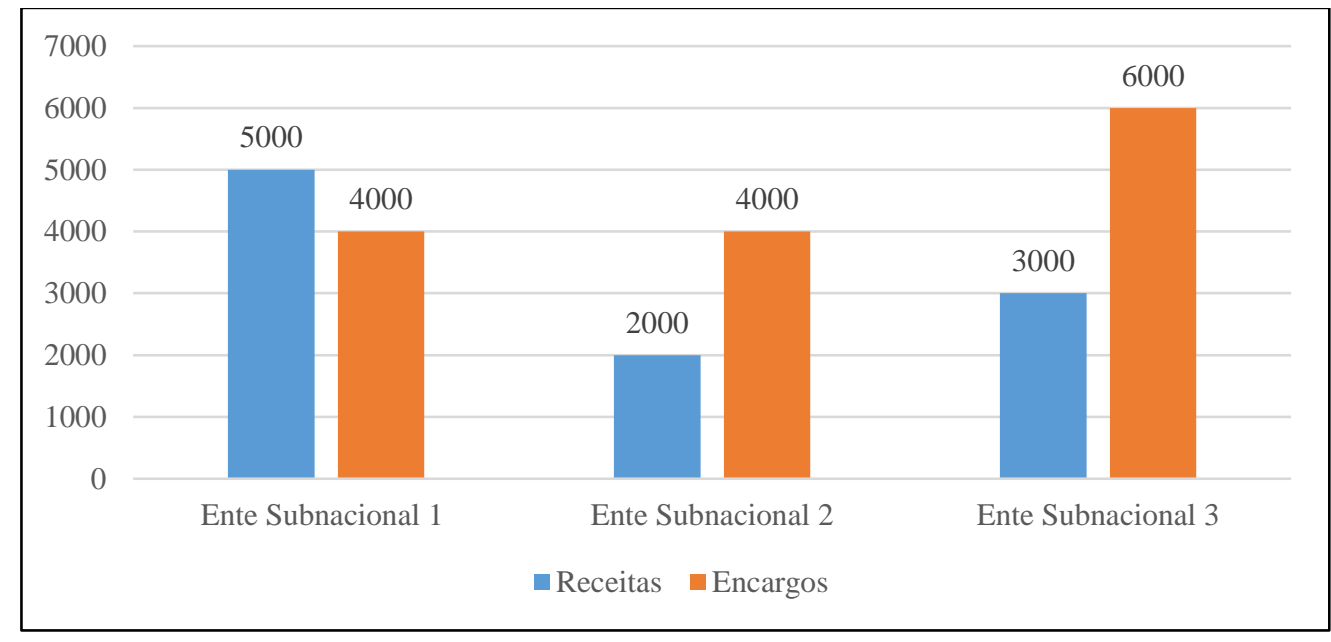

Fonte: Elaboração Própria.

As transferências condicionadas resultam da função do governo de promover certos setores que são de extrema importância nacional. Costuma-se estimular e financiar com tais recursos projetos de infraestrutura e os chamados bens meritórios, ou seja, bens que tem grande impacto social e que devem ser providos pelo poder público a fim de que a população de menor renda não seja excluída de seu consumo, exemplificados pelos setores de saúde e educação. Tais transferências são constitucionalmente estabelecidas com critérios prévios e cabe ao governo local apresentar contrapartidas para evitar influências políticas.

Por último, as transferências voluntárias se caracterizam também por serem destinadas a setores, obras ou serviços que possuem o interesse do governo central. Todavia, estes são estabelecidos ano a ano através do orçamento do governo e não tendo qualquer obrigatoriedade estipulada por lei. Com isso, tais recursos podem sofrer influências políticas quanto a sua alocação.

Os recursos das transferências devolutivas e redistributivas são livres, ou seja, eles podem ser utilizados de qualquer forma pelas jurisdições, já as condicionadas e voluntárias só podem ser gastas nos setores específicos para os quais elas foram destinadas. Dessa forma, entende-se que, em uma federação, quanto maior for a porcentagem dos orçamentos subnacionais com transferências condicionadas e voluntárias, menor será a autonomia dos mesmos e mais centralizado e dependente é o país em relação ao seu governo central. Do mesmo modo, quanto maior a participação de transferências devolutivas e menor for as redistributivas, tal federação terá menor interferência e menor poder de diminuir as desigualdades regionais (PRADO, 2006a). 


\subsection{Fluxos Redistributivos e Sistemas de Equalização}

Tratando-se dos mecanismos de equalização entre os entes, Prado (2006a) os difere entre fluxos redistributivos e sistemas de equalização. Complementarmente, discute acerca da forma institucional que determina tais dispositivos, podendo ser definido pelo governo central ou por um corpo governamental específico que, dotado de certa autonomia, diminui a potencialidade de ocorrer interferências políticas no processo decisório.

Os fluxos redistributivos caracterizam-se por utilizar critérios exógenos às formas de financiamento dos entes os quais serão beneficiados. Tais critérios são demasiadamente simples, como população, renda per capita ou formas de matching grants (igualar o preço unitário final do bem) que funcionam de forma eficaz para transferências condicionadas, mas, se usado com o intuito de igualar a capacidade de gasto dos governos locais, podem gerar grandes iniquidades.

Já os sistemas de equalização, possuem formas mais complexas de estabelecer os montantes referentes às transferências. Estes internalizam em seus critérios as diferentes formas e possibilidades de receitas dos governos de nível inferior para poder estabelecer a quantia a qual cada um terá direito. Tais mecanismos são mais custosos e complexos que os fluxos redistributivos, todavia estes conseguem atingir com maior precisão os objetivos de proporcionar maior equidade na capacidade final de gasto das jurisdições.

Em relação aos critérios dos sistemas de equalização, encontra-se duas maneiras distintas de se almejar os objetivos de equidade, a partir do princípio da capacidade total de gasto e do princípio da equalização pelas necessidades fiscais (PRADO, 2006a).

O princípio da capacidade total de gasto distribui as transferências a partir da capacidade fiscal de cada ente, buscando igualar as receitas totais per capita. Porém, é necessário levar em conta a receita potencial de cada governo, ao invés da efetiva, pela possibilidade de inibir o esforço fiscal dos mesmos, visto que suas receitas seriam cobertas pelas transferências. Além disso, tal princípio não é suficiente para países muito desiguais, pois as diferenças de custos dos bens e serviços não são levadas em conta nesse processo.

Já o princípio da equalização das necessidades fiscais define previamente a cesta de bens e serviços que serão providos e, a partir da estimação do custo da cesta em cada jurisdição, é então definido o valor das transferências. Tal critério internaliza os gastos díspares de provisão e se adequa da melhor forma aos países que possuem grandes desigualdades em seus territórios. Entretanto, é necessária a mensuração precisa das condições de cada jurisdição, como o nível de salários e os custos dos bens, que nem sempre são de fácil 
apreciação, principalmente em federações pouco desenvolvidas ou com um nível de complexidade espacial e territorial elevado.

É preciso destacar a pluralidade e os diferentes arranjos federativos entre os países que adotam tal modelo de organização. O nível de descentralização, a importância dada a noções de eficiência, equidade ou redistribuição são distintas entre as federações, por este se dar a partir da evolução histórica influenciada pelo processo de desenvolvimento, formações políticas de diferentes épocas e por singularidades. Questões como tamanho do território, heterogeneidade da cultura, da população, distribuição geográfica dos centros dinamizadores da economia e nível de renda, influenciam o produto final das relações entre as camadas de governo.

Dessa forma, é impossível o estabelecimento de uma fórmula ideal de federalismo, com a existência constante de trade-off's entre alocação eficiente, redistribuição ou estabilização. Contudo, é de fundamental importância observar as experiências internacionais e buscar 0 compartilhamento de saberes a fim de reproduzir práticas eficientes que estejam em harmonia com as demandas dos residentes da federação em questão. Busca-se então, para o caso brasileiro, analisar os critérios de alocação de recursos do Fundo de Participação dos Municípios - FPM, transferência de caráter redistributivo que visa diminuir as desigualdades à nível municipal.

\section{MÉTODO}

O Fundo de Participação dos Municípios foi criado no Código Tributário de 1966, durante o regime militar, e contava inicialmente com alíquotas de 10\% sobre as arrecadações dos impostos de renda e produtos industrializados. Este caracteriza-se por ser uma transferência intergovernamental não vinculada a nenhum setor e que tem por intuito ser um mecanismo redistributivo para diminuir as diferenças entre os orçamentos dos municípios brasileiros.

Ao longo do tempo, as alíquotas foram se alterando, sua evolução está descrita na tabela 1 a seguir. Durante o período militar logo após a sua criação, em 1968, as participações dos municípios caíram de 10\% para 5\%, com evoluções ao longo do período, chegando ao fim do regime autoritário em um patamar de $16 \%$. Com o regime democrático e a constituição de 1988, as pressões de estados e municípios por autonomia se traduziram também na elevação de seus percentuais referentes aos impostos que financiam tal fundo, este chegando a $22,5 \% \mathrm{em}$ 1993.

Recentemente, com as emendas constitucionais 55/2007 e 84/2014, houve um acréscimo de $1 \%$ pagos no primeiro decêndio de dezembro e $1 \%$ pagos no primeiro decêndio de julho, respectivamente. Tais aumentos podem ser justificados pela diminuição das receitas do IPI 
quando comparadas a arrecadação total da União. De 2002 para 2015, sua participação nas receitas tributárias do governo federal passou de $5,6 \%$ para 3,7\% muito em consequência das renúncias fiscais de tal tributo.

Tabela 1 - Variação temporal do percentual da arrecadação do IR e IPI destinado ao FPM

\begin{tabular}{lrr}
\hline \multicolumn{1}{c}{ Dispositivo Legal } & \multicolumn{1}{c}{ FPM (\%) } & \multicolumn{1}{c}{ Vigência } \\
\hline Código Tributário Nacional (1966) & 10,0 & $1967 / 68$ \\
\hline Ato Complementar 40/1968 & 5,0 & $1969 / 75$ \\
\hline & 6,0 & 1976 \\
\cline { 2 - 3 } Emenda Constitucional 5/1975 & 7,0 & 1977 \\
\cline { 2 - 3 } & 8,0 & 1978 \\
\hline \multirow{2}{*}{ Emenda Constitucional 17/1980 } & 9,0 & $1979 / 80$ \\
\hline \multirow{2}{*}{ Emenda Constitucional 23/1983 } & 10,0 & 1981 \\
\hline Emenda Constitucional 27/1985 & 10,5 & $1982 / 83$ \\
\hline & 13,5 & 1984 \\
\cline { 2 - 3 } Constituição Federal de 1988 & 16,0 & 1985 \\
\cline { 2 - 3 } & 17,0 & $1985 / 88$ \\
\cline { 2 - 3 } & 20,0 & 19881 \\
\hline Emenda Constitucional 55/2007 & 20,5 & 1989 \\
\hline Emenda Constitucional 84/2014 & 21,0 & 1990 \\
\hline Fon & 21,5 & 1991 \\
\hline
\end{tabular}

Fonte: STN - Ministério da Fazenda, 2012; atualizada pelo autor

Notas:

${ }^{1}$ A partir da promulgação da Constituição.

${ }^{2} \mathrm{Em} 2007$, a partir da arrecadação do mês de setembro.

${ }^{3} \mathrm{~A}$ partir de janeiro de 2015.

Partindo para os critérios de distribuição do fundo2 ${ }^{2}$, este restringe $10 \%$ dos recursos para as capitais dos estados, $3,6 \%$ para os chamados municípios de reserva (com população acima de 142.632 habitantes), e os $86,4 \%$ restantes aos municípios de interior. Há de se colocar que os municípios de reserva também são inseridos no cálculo dos municípios de interior, sendo os $3,6 \%$ um percentual extra a esses municípios.

Em relação aos critérios de repasse dos 10\% referentes à capital e 3,6\% destinados aos municípios de reserva, leva-se em conta a população da capital e do município de reserva e o inverso da renda per capita do estado ao qual o município está inserido.

Em relação aos municípios de interior, os valores correspondentes a cada estado já estão estipulados e estão congelados sem sofrer mudanças desde 1990 conforme tabela 2. Dentro de cada estado, o único critério estabelecido é a variável população em que cada município possui determinado coeficiente em relação ao seu número de habitantes (Tabela 3).

\footnotetext{
2 Para mais informações sobre os critérios de distribuição do FPM ver a cartilha do Tesouro Nacional, disponível em <http://www.tesouro.fazenda.gov.br/documents/10180/329483/pge_cartilha_fpm.pdf>. Acesso em 14 mai 2019.
} 
Tal coeficiente é dividido pelo total de coeficientes do estado resultando na sua participação percentual em relação ao montante destinado ao seu estado.

Tais percentuais podem variar de acordo com a alteração da renda per capita dos estados, do número de municípios, ambos os dados divulgados pelo IBGE, além de alterações caso haja criação de novos municípios.

Tabela 2 - Participação dos estados no total a distribuir do FPM Interior

\begin{tabular}{lrlr}
\hline \multicolumn{1}{c}{ Estado } & Participação $\%$ & \multicolumn{1}{c}{ Estado } & Participação \% \\
\hline Acre & 0,2630 & Paraíba & 3,1942 \\
\hline Alagoas & 2,0883 & Paraná & 7,2857 \\
\hline Amapá & 0,1392 & Pernambuco & 4,7952 \\
\hline Amazonas & 1,2452 & Piauí & 2,4015 \\
\hline Bahia & 9,2695 & Rio de Janeiro & 2,7379 \\
\hline Distrito Federal & 0,0000 & Rio Grande do Norte & 2,4324 \\
\hline Ceará & 4,5864 & Rio Grande do Sul & 7,3011 \\
\hline Espírito Santo & 1,7595 & Rondônia & 0,7464 \\
\hline Goiás & 3,7318 & Roraima & 0,0851 \\
\hline Maranhão & 3,9715 & Santa Catarina & 4,1997 \\
\hline Mato Grosso & 1,8949 & São Paulo & 14,2620 \\
\hline Mato Grosso do Sul & 1,5004 & Sergipe & 1,3342 \\
\hline Minas Gerais & 14,1846 & Tocantins & 1,2955 \\
\hline Pará & 3,2948 & Total & 100,0000 \\
\hline
\end{tabular}

Fonte: STN - Ministério da Fazenda, 2012. Resolução TCU nº 242/90, de 2 de janeiro de 1990.

Tabela 3 - Coeficientes por faixas de habitantes do FPM interior

\begin{tabular}{lrlr}
\hline \multicolumn{1}{c}{ Faixa de habitantes } & Coeficiente & Faixa de habitantes & \multicolumn{1}{c}{ Coeficiente } \\
\hline Até 10.188 & 0,6 & De 61.129 a 71.316 & 2,4 \\
\hline De 10.189 a 13.584 & 0,8 & De 71.317 a 81.504 & 2,6 \\
\hline De 13.585 a 16.980 & 1,0 & De 81.505 a 91.692 & 2,8 \\
\hline De 16.981 a 23.772 & 1,2 & De 91.693 a 10.1880 & 3,0 \\
\hline De 23.773 a 30.564 & 1,4 & De 101.881 a 115.464 & 3,2 \\
\hline De 30.565 a 37.356 & 1,6 & De 115.465 a 129.048 & 3,4 \\
\hline De 37.357 a 44.148 & 1,8 & De 129.049 a 142.632 & 3,8 \\
\hline De 44.149 a 50.940 & 2,0 & De 142.633 a 156.216 & 4,0
\end{tabular}

Fonte: STN - Ministério da Fazenda, 2012. Decreto Lei no 1.881/1981.

A análise deste trabalho consiste na investigação acerca dos níveis de equidade que o FPM proporciona aos municípios dos estados do Pará e Minas Gerais. Tal busca baseia-se no texto de Prado (2006b) em que este coloca que os critérios exógenos do FPM não alcançam seus objetivos de aproximar as receitas per capita dos municípios brasileiros por não levarem em consideração as outras fontes de financiamento dos mesmos.

A partir dessa premissa estabelecida, busca-se averiguar quais as principais fontes de financiamento dos municípios e como estas se comportam a partir de faixas populacionais, critério este preponderante na partilha de recursos do FPM. Para tal verificação, utiliza-se a abordagem per capita em todas as fontes de receita analisadas, pois assim se espera 
internalizar na análise o tamanho das demandas de bens e serviços, além de que a apreciação pelo número de habitantes permite uma melhor observação dos níveis de equidade obtidos, pois identifica-se o quanto de recursos cada município terá disponível para cada um de seus habitantes.

Colocado isto, é possível analisar quais os graus de concentração e desconcentração de receitas correntes geradas por cada uma das fontes estudadas (receita tributária, Cota-Parte ICMS, CFEM, SUS, FUNDEB), conforme o número de residentes nos municípios e, após analisar o resultado das fontes sem o FPM, introduz-se os montantes de tal fundo a fim de observar como este se insere nos orçamentos municipais e quais níveis redistributivos ou de equalização da receita corrente per capita este consegue lograr em cidades de estados de regiões distintas de nível de desenvolvimento.

Para o uso das faixas populacionais, utilizou-se os intervalos de habitantes dos coeficientes da tabela 3 como base, contudo como as faixas são muitas e para análise gráfica ficaria de difícil visualização, estas foram agrupadas de dois em dois, gerando nove intervalos populacionais. Além desses nove, foi introduzido também a capital na análise, totalizando 10 faixas de habitantes conforme visto na tabela 4. Observa-se que a penúltima faixa de municípios corresponde aos municípios de reserva, aqueles acima de 142.632.

As informações foram obtidas do sistema Finanças do Brasil - FINBRA que consta no sítio eletrônico da Secretaria do Tesouro Nacional. Os dados obtidos referem-se às receitas brutas orçamentárias dos municípios, ou seja, sem serem descontadas as deduções. Tal uso das receitas brutas se justifica pelo principal objetivo do trabalho de abordar a distribuição dos recursos entre municípios e estados, sem ser usado os valores para comparação com outros anos.

Foram utilizados os dados de 2017, os quais possuíam informações para 124 municípios para o estado do Pará ( $86,1 \%$ do total) e 851 para o estado de Minas Gerais (99,8\% do total). Além disso, a população estudada no estado do Pará pela soma dos residentes nos municípios estudados corresponde a $91,1 \%$ da população paraense e $99,2 \%$ da mineira, segundo as estimativas populacionais do IBGE para o ano de 2017.

Tabela 4 - Municípios e população estudados dos estados de Pará e Minas Gerais em 2017 Quantitativo e \%.

\begin{tabular}{ccccccccc}
\hline \multirow{2}{*}{$\begin{array}{c}\text { Faixas de } \\
\text { Habitantes }\end{array}$} & \multicolumn{2}{c}{$\begin{array}{c}\text { Número de } \\
\text { Municípios }\end{array}$} & \multicolumn{2}{c}{ Município (\%) } & \multicolumn{2}{c}{ População } & \multicolumn{2}{c}{ População (\%) } \\
\cline { 2 - 10 } & PA & MG & PA & MG & PA & MG & PA & MG \\
\hline Até 13.584 & 17 & 572 & 13,7 & 67,2 & 151.422 & 3.663 .595 & 1,99 & 17,48 \\
\hline $\begin{array}{c}\text { De 13.585 a } \\
\text { 23.772 }\end{array}$ & 21 & 123 & 16,9 & 14,5 & 373.881 & 2.185 .989 & 4,90 & 10,43 \\
\hline
\end{tabular}




\begin{tabular}{ccccccccc}
\hline $\begin{array}{c}\text { De 23.773 a } \\
\mathbf{3 7 . 3 5 6}\end{array}$ & 31 & 60 & 25,0 & 7,1 & 900.548 & 1.738 .029 & 11,81 & 8,29 \\
\hline $\begin{array}{c}\text { De 37.357 a } \\
\mathbf{5 0 . 9 4 0}\end{array}$ & 16 & 28 & 12,9 & 3,3 & 688.977 & 1.202 .264 & 9,03 & 5,74 \\
\hline $\begin{array}{c}\text { De } \mathbf{5 0 . 9 4 1} \text { a } \\
\mathbf{7 1 . 3 1 6}\end{array}$ & 20 & 17 & 16,1 & 2,0 & 1.183 .062 & 1.031 .105 & 15,51 & 4,92 \\
\hline $\begin{array}{c}\text { De 71.317 a } \\
\mathbf{9 1 . 6 9 2}\end{array}$ & 3 & 14 & 2,4 & 1,6 & 232.623 & 1.164 .039 & 3,05 & 5,55 \\
\hline $\begin{array}{c}\text { De } \mathbf{9 1 . 6 9 3} \text { a } \\
\mathbf{1 1 5 . 4 6 4}\end{array}$ & 4 & 12 & 3,2 & 1,4 & 416.217 & 1.216 .845 & 5,46 & 5,81 \\
\hline $\begin{array}{c}\text { De 115.465 a } \\
\mathbf{1 4 2 . 6 3 2}\end{array}$ & 5 & 8 & 4,0 & 0,9 & 619.948 & 1.028 .193 & 8,13 & 4,91 \\
\hline $\begin{array}{c}\text { Acima de } \\
\mathbf{1 4 2 . 6 3 2}\end{array}$ & 6 & 16 & 4,8 & 1,9 & 1.612 .977 & 5.214 .664 & 21,15 & 24,88 \\
\hline Capital & 1 & 1 & 0,8 & 0,1 & 1.446 .042 & 2.513 .451 & 18,96 & 11,99 \\
\hline Total & 124 & 851 & 100,0 & 100,0 & 7.625 .697 & 20.958 .174 & 100,00 & 100,00 \\
\hline
\end{tabular}

Fonte: Finanças do Brasil - FINBRA. STN - Ministério da Fazenda, 2018. Elaboração Própria.

\section{FPM E A EQUALIZAÇÃO DAS RECEITAS PER CAPITA DOS MUNICÍPIOS DOS ESTADOS DE PARÁ E MINAS GERAIS NO ANO DE 2017}

\subsection{Receita Tributária}

Analisando a receita tributária dos municípios estudados, ou seja, a capacidade de arrecadação autônoma deles, identifica-se, nos municípios do Pará, grande concentração da receita tributária per capita em Belém, contudo discrepâncias grandes são detectadas na terceira e quarta faixa populacionais (De 23.773 a 37.356 e de 37.357 a 50.940), sendo a primeira elevada comparativamente aos municípios de faixas populacionais vizinhas por conta de estar na mesma o município de Canaã dos Carajás, importante município minerador paraense. A segunda podendo ter correlação a elevada receita tributária do município de Jacareacanga pela usina hidrelétrica de Teles Pires.

Figura 3 - Receita Tributária per capita dos municípios do Pará por faixas de habitantes - 2017 $-\mathrm{R} \$$

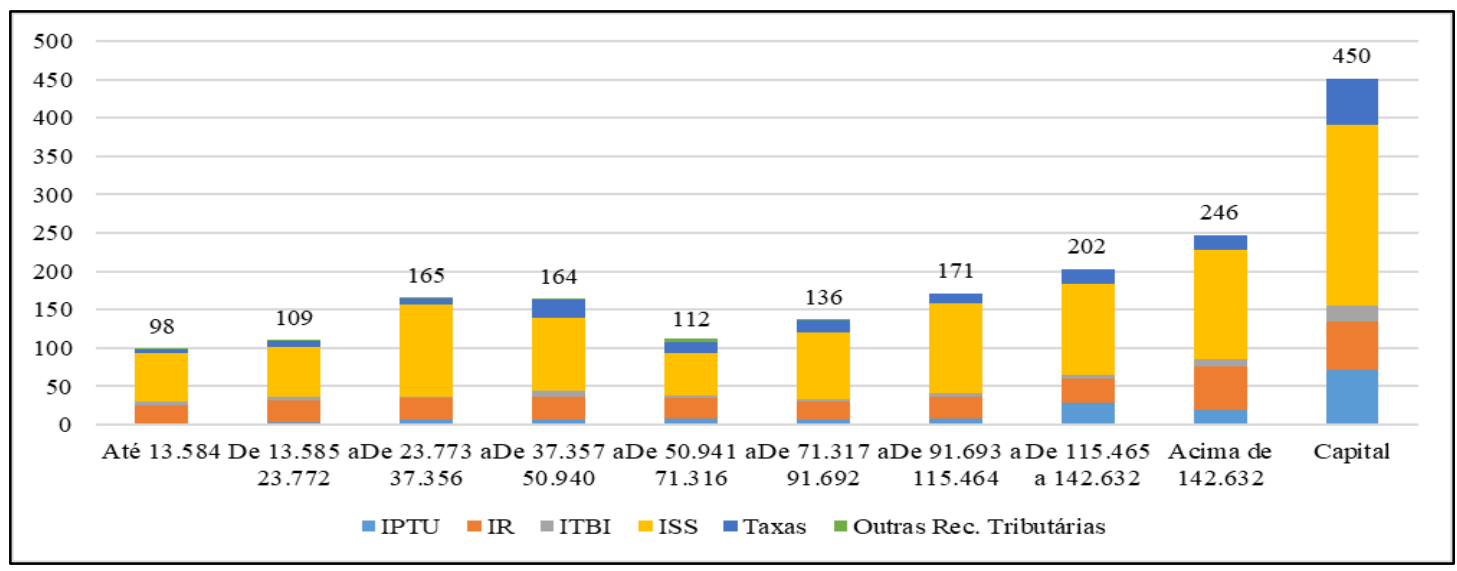

Fonte: Finanças do Brasil - FINBRA. STN - Ministério da Fazenda, 2018. Elaboração Própria. 
Em relação a Minas Gerais, este apresenta menos distorções nas distribuições per capita de receita entre as faixas populacionais (não levando em consideração Belo Horizonte com valores muito acima do que os demais). Discrepâncias são identificadas apenas na faixa seis com valores maiores que as faixas sequentes. Nessas faixas, estão inseridos importantes municípios mineradores como Ouro Preto e Nova Lima, além de cidades com forte atividade agrícola e pecuária como Alfenas e Patrocínio. (Figura 4).

Figura 4 - Receita Tributária per capita dos municípios de Minas Gerais por faixas de habitantes $-2017-\mathrm{R} \$$

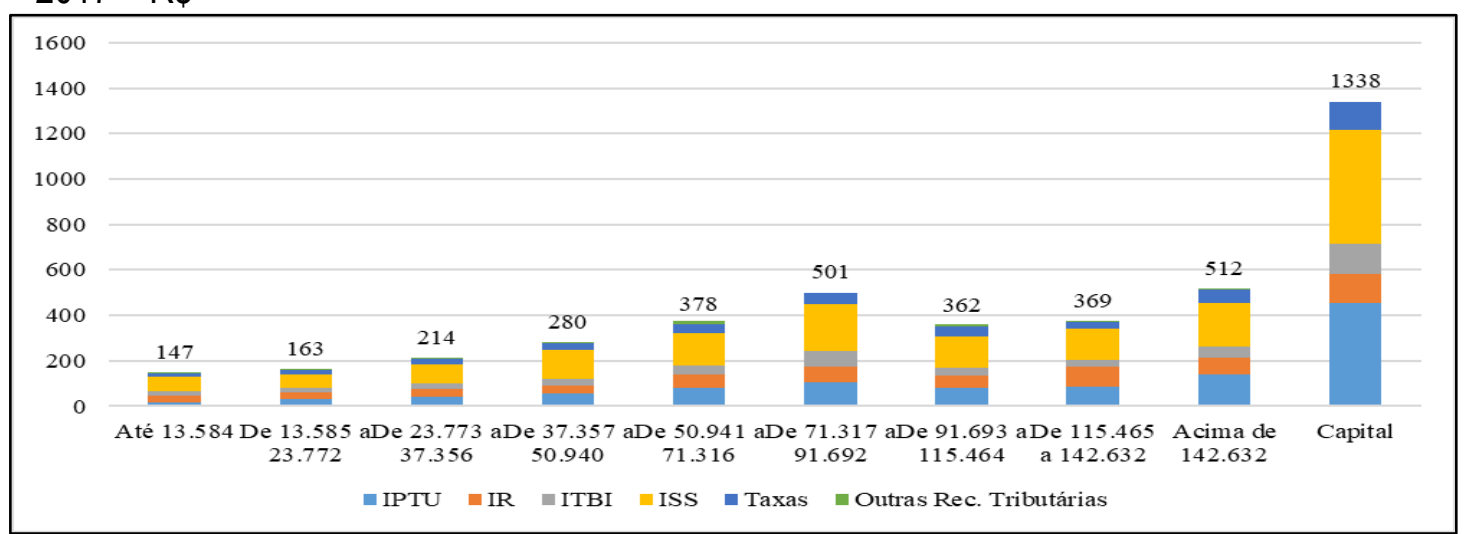

Fonte: Finanças do Brasil - FINBRA. STN - Ministério da Fazenda, 2017. Elaboração Própria.

Nos dois estados nota-se o ISS como tributo com maior peso nos orçamentos tributários, o IR tendo maior peso nos municípios menores e o IPTU ganha força com a concentração urbana. Outro ponto em questão que pode ser levantado são as receitas tributárias per capita municipais serem maiores no estado de Minas Gerais que no Pará. Guedes (2007) coloca que os tributos municipais são demasiadamente urbanos e municípios com grande extensão territorial rural, como acontece no Pará, pouco tem o que tributar. Tal relação pode ser vista na figura a seguir que compara o grau de urbanização dos municípios dos dois estados.

Figura 5 - Participação da população urbana em relação a geral dos municípios de Pará e Minas Gerais por faixas de habitantes - 2010 - \%

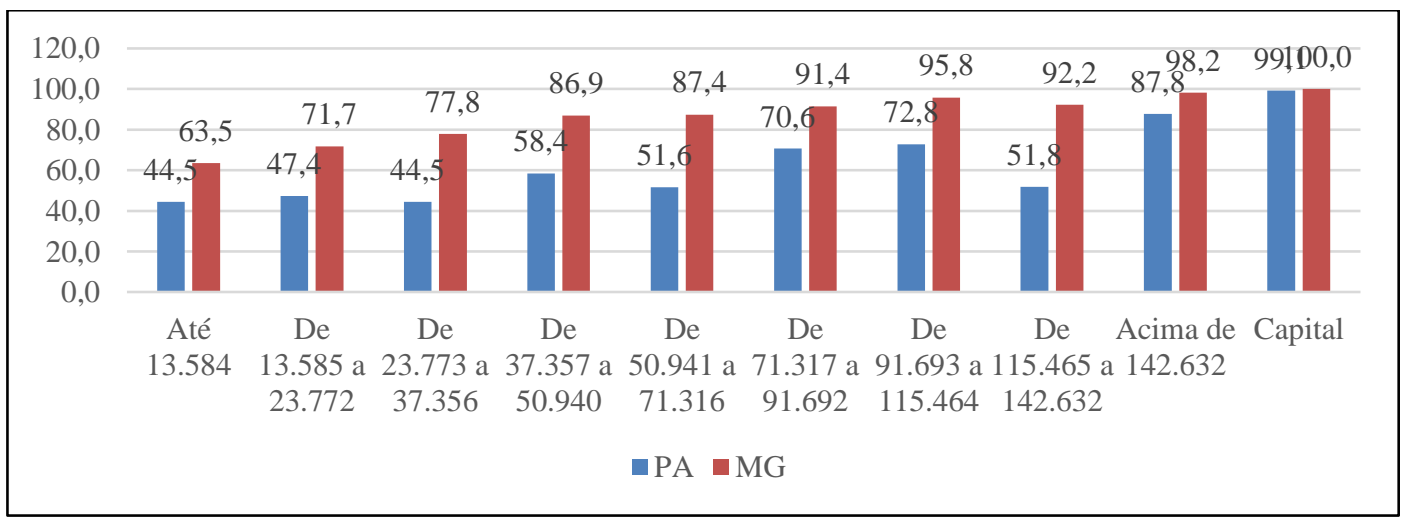

Fonte: Censo Demográfico 2010, IBGE. Elaboração Própria. 


\subsection{Cota-Parte ICMS E Lei Kandir}

Em relação à cota-parte ICMS, como já visto, essa traduz principalmente 0 valor adicionado dos municípios e um comportamento crescente das receitas per capita em relação ao tamanho da população é esperado. Contudo, identifica-se uma distribuição per capita mais igualitária entre os municípios de Minas Gerais em relação ao Pará, sendo neste último encontrado municípios muito prejudicados, como os das faixas 4, 5 e 6 (Figura 6).

Figura 6 - Receita per capita da Cota-Parte ICMS nos municípios dos estados de Pará e Minas Gerais por faixas populacionais $-2017-\mathrm{R} \$$

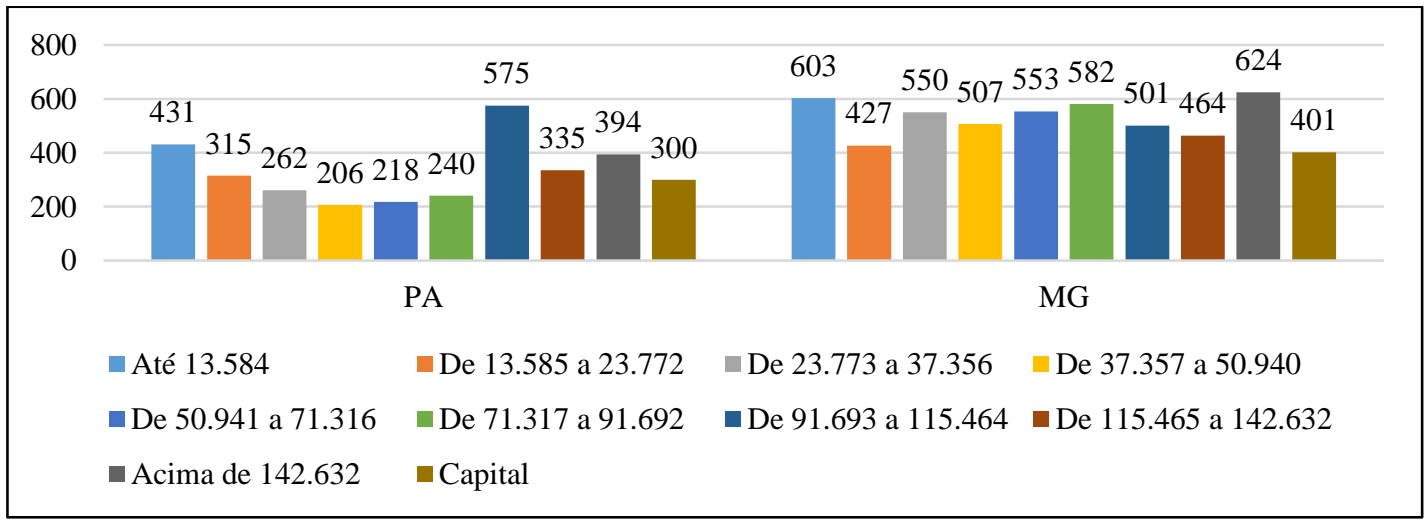

Fonte: Finanças do Brasil - FINBRA. STN - Ministério da Fazenda, 2018. Elaboração Própria.

A melhor distribuição nos municípios mineiros pode ser explicada quando comparamos os critérios de repasse da cota-parte conforme tabela 5. Os critérios paraenses limitam-se ao valor adicionado, à área geográfica, à população e a uma parcela dividida em partes iguais. Já em relação aos parâmetros mineiros, com a chamada lei Robin Hood (Lei estadual 18.030/09), há uma maior complexidade nos mesmos, com mecanismos de desconcentração de receitas, incentivos à exploração das bases tributárias e investimento em áreas sociais básicas. (RIANI, 2014).

Tabela 5 - Critérios e seus respectivos pesos na distribuição da Cota-Parte ICMS no Pará e Minas Gerais.

\begin{tabular}{lrrr}
\hline & \multirow{2}{*}{ Variáveis } & \multicolumn{2}{c}{ Pesos } \\
\cline { 2 - 4 } & PA & MG \\
\hline VAF - Valor Adicionado Fiscal & 75 & 75 \\
\hline Divisão em partes iguais & 15 & - \\
\hline Área Geográfica & 5 & 1 \\
\hline População & 5 & 2,7 \\
\hline População 50 mais populosos & - & 2 \\
\hline Educação & - & 2 \\
\hline Produção de Alimentos & - & 1 \\
\hline Patrimônio Cultural & - & 1 \\
\hline Meio Ambiente & - & 1,1 \\
\hline
\end{tabular}




\begin{tabular}{lrr}
\hline Gastos com Saúde & - & 2 \\
\hline Receita Própria & - & 1,9 \\
\hline Cota Mínima & - & 5,5 \\
\hline Municípios Mineradores & - & 0,01 \\
\hline Recursos Hídricos & - & 0,25 \\
\hline Sede Estabelecimentos Penitenciários & - & 0,1 \\
\hline Esportes & - & 0,1 \\
\hline Turismo & - & 0,1 \\
\hline ICMS solidário & - & 4,14 \\
\hline Mínimo per capita & - & 0,1 \\
\hline
\end{tabular}

Fonte: PA - Lei nº 6.276 de 1999 e MG - Lei nº 18.030 de 2009. Elaboração Própria.

Outro ponto que afeta também a cota-parte do ICMS dos estados estudados refere-se às consequências da Lei 87/1996, a chamada Lei Kandir. Pará e Minas Gerais são dois dos maiores afetados por tal lei por suas economias terem grande relação com a exportação de produtos primários e semielaborados, e as compensações das receitas não serem suficientes para cobrir suas perdas (RIANI; ALBUQUERQUE, 2000). Conforme mapa abaixo elaborado pela FAPESPA (2017), é possível identificar que Pará e Minas Gerais são alguns dos maiores afetados por tal lei desde sua implementação até 2016.

Figura 7 - Mapa das perdas acumuladas ${ }^{3}$ de arrecadação do ICMS com a Lei Kandir - 1997 a 2016.

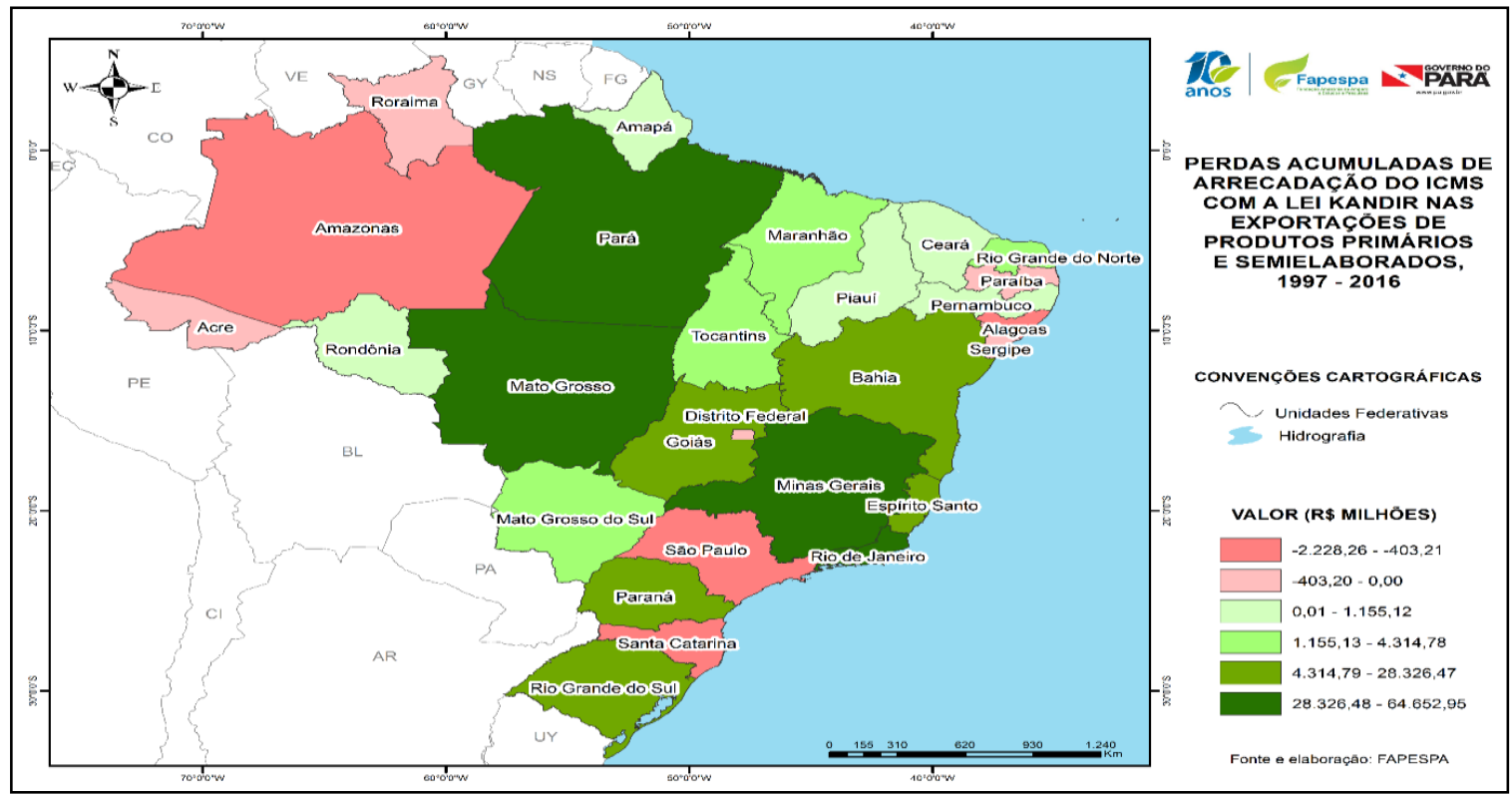

Fonte: FAPESPA, 2017.

Sales (2010) pondera colocando que, em relação ao Pará, as perdas são ainda mais sentidas pelo maior peso que as desonerações representam na arrecadação do ICMS, afetando

\footnotetext{
3 No mapa há as chamadas "perdas negativas", ou seja, as compensações foram maiores que as perdas obtidas por estes estados, explicando assim os valores negativos de perdas em certos estados. Para mais informações a respeito, ler a nota técnica da FAPESPA disponível em < http://www.fapespa.pa.gov.br/upload/Arquivo/anexo/1366.pdf?id=1497373099>. Acesso em 24 dez de 2017.
} 
o montante total destinado ao repasse. Além disso, o autor ainda afirma que todos os municípios paraenses são afetados pelas desonerações, não só da lei Kandir, como também de incentivos fiscais e que, no momento da distribuição das compensações e royalties, os municípios mineradores são beneficiados pelo seu maior valor agregado, aumentando ainda mais os desequilíbrios entre as cidades do estado.

\subsection{Royalties da CFEM}

Os royalties da CFEM têm como intuito indenizar os entes subnacionais pela exploração dos recursos minerais. Esta incide sobre o faturamento líquido das empresas mineradoras e variam de acordo com o mineral (tabela 6), seus critérios de distribuição destinam $65 \%$ de sua receita ao município produtor, $23 \%$ aos estados e $12 \%$ à União. Tais recursos referentes aos munícipios devem ser gastos em projetos que revertam em prol da comunidade, melhorando a infraestrutura e não podem ser usados para pagamentos de dívidas ou de pessoal. (CNM, 2012).

Tabela 6 - Alíquotas da CFEM por tipo de minério

\begin{tabular}{ll}
\hline Alíquota & Substância \\
\hline $\mathbf{3} \%$ & minério de alumínio, manganês, sal-gema e potássio \\
\hline $\mathbf{2} \%$ & ferro, fertilizante, carvão, demais substâncias \\
\hline $\mathbf{1 \%}$ & ouro \\
\hline $\mathbf{0 , 2 0 \%}$ & pedras preciosas, pedras coradas lapidáveis, carbonetos e metais nobres \\
\hline
\end{tabular}

Fonte: CNM, 2012.

Enríquez (1998) critica a incidência sobre o faturamento ser feito sobre o faturamento líquido e não sobre o bruto pela dificuldade de mensuração e carência de dados das empresas sobre custos e lucros. Além disso, a mesma coloca a discrepâncias das alíquotas em vigência no Brasil quando comparadas a outros países que também possuem perfil extrativista, tais dados estão contidos no quadro 1.

Quadro 1 - Royalties da exploração mineral: uma análise comparativa entre EUA, Canadá, Venezuela e Brasil

\begin{tabular}{|c|c|c|c|c|}
\hline Questão/país & EUA & Canadá & Venezuela & Brasil \\
\hline $\begin{array}{l}\text { Que taxa é } \\
\text { adotada? }\end{array}$ & $5 \%$ a $12,5 \%$ & $3 \%$ a $9 \%$ & $1 \%$ a $4 \%$ & $1 \%$ a $3 \%$ \\
\hline $\begin{array}{l}\text { A taxa varia em } \\
\text { função de quê? }\end{array}$ & $\begin{array}{l}\text { 1. recurso mineral; } \\
\text { 2. tipo de propriedade; }\end{array}$ & $\begin{array}{l}\text { 1. recurso mineral, } \\
\text { 2. teor da jazida, } \\
\text { 3. retorno do } \\
\text { capital investido }\end{array}$ & $\begin{array}{l}\text { 1. recurso } \\
\text { mineral; } \\
\text { 2. teor da } \\
\text { jazida, }\end{array}$ & 1. recurso mineral, \\
\hline $\begin{array}{ll}\text { Como } & \text { se } \\
\text { denomina? } & \end{array}$ & customary royalty rate & $\begin{array}{l}\text { provincial mining } \\
\text { tax }\end{array}$ & $\begin{array}{l}\text { taxa de lavra/ } \\
\text { royalty }\end{array}$ & $\begin{array}{l}\text { compensação } \\
\text { financeira sobre a } \\
\text { exploração mineral } \\
\text { (CFEM); royalty }\end{array}$ \\
\hline $\begin{array}{ll}\text { Qual a base } & \text { de } \\
\text { incidência } & \text { da }\end{array}$ & receita bruta & $\begin{array}{lll}\text { receita } & \text { bruta } & \mathrm{e} \\
\text { líquida } & & \end{array}$ & receita bruta & faturamento líquido \\
\hline
\end{tabular}




\begin{tabular}{|c|c|c|c|c|}
\hline taxa? & & & & \\
\hline $\begin{array}{l}\text { Como se distribui } \\
\text { entre os } \\
\text { beneficiários? }\end{array}$ & 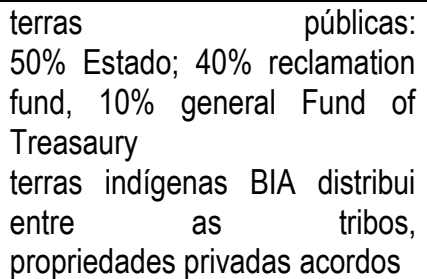 & $\begin{array}{l}\text { Províncias são as } \\
\text { proprietárias } \\
\text { estabelecem } \\
\text { critérios próprios }\end{array}$ & - & $\begin{array}{lr}65 \% & \text { Município } \\
23 \% & \text { Estado } \\
12 \% \text { União } & \end{array}$ \\
\hline
\end{tabular}

Fonte: ENRÍQUEZ (1998) a partir de informações: EUA: Mineral Revenues, 1995 (US Department of the Interior); Canadá: BOADWAY et al. (1989); Venezuela e Brasil: BRASIL. Ministério das Minas e Energia (1992).

Partindo-se para análise dos dados referentes à CFEM dos estados estudados, observase que estes ajudam a explicar as diferenças encontradas nas receitas tributárias. Observa-se, no Pará, que os recursos referentes à extração mineral estão muito concentrados na penúltima faixa populacional, onde estão inseridos os municípios de Parauapebas e Marabá. Também há grande receitas de tal fonte nos municípios de Canaã do Carajás, Oriximiná, Curionópolis e Paragominas. Já as receitas per capita dos municípios mineiros, estão mais desconcentradas e também aparecem em municípios de menor população, seus principais arrecadadores, no ano de 2017, foram Nova Lima, Congonhas, Itabira, São Gonçalo do Rio Abaixo e Mariana (Figura 8).

Figura 8 - Receita per capita dos royalties da CFEM nos municípios dos estados de Pará e Minas Gerais por faixas populacionais - $2017-\mathrm{R} \$$

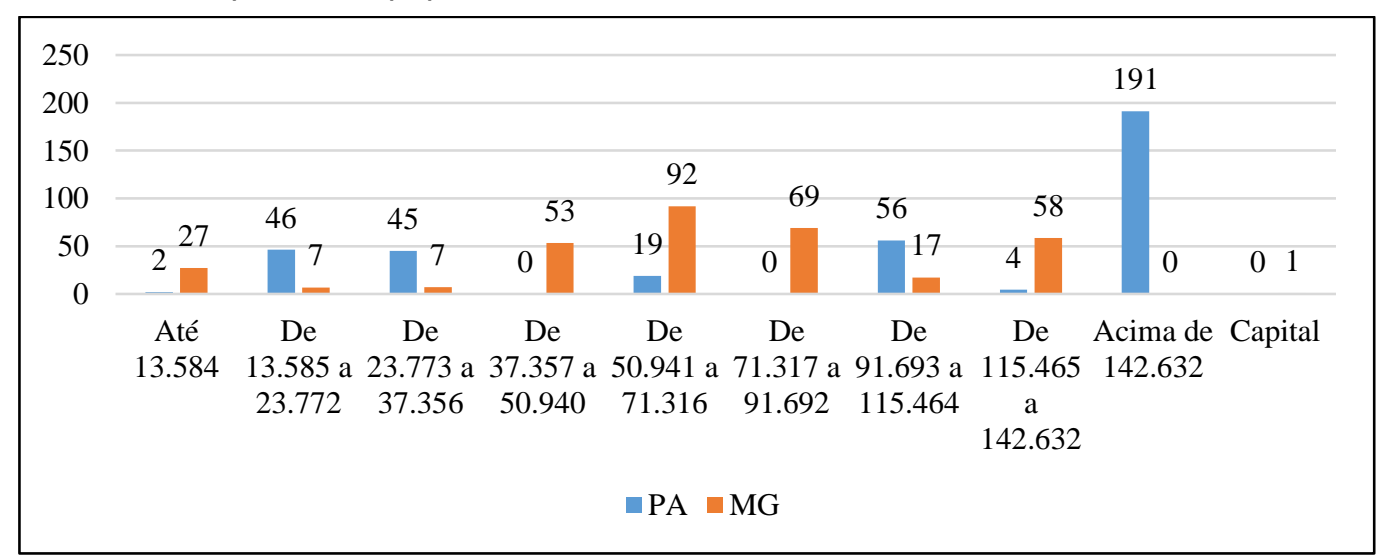

Fonte: Finanças do Brasil - FINBRA. STN - Ministério da Fazenda, 2018. Elaboração Própria.

Brás (1992 apud ENRÍQUEZ, 1998) coloca que os royalties possuem elementos concentradores de renda por beneficiarem os municípios que já são favorecidos com a geração de emprego e maior dinamização da economia. Ao se transferir a maior parte dos recursos aos municípios mineradores, há grandes dificuldades de uso dos mesmos como elemento redistributivo e de interferência nas cidades que não são mineradoras, mas que também sofrem externalidades negativas resultantes da atividade extrativista. 
Contudo, Trindade (2011) acrescenta colocando que os municípios mineradores sofrem com as desonerações e um maior contingenciamento populacional, aumentando demasiadamente os encargos dos municípios, além de que os recursos são escassos pelas baixas alíquotas estabelecidas e o destino dos mesmos são de difícil controle. Assim, ressalta-se que os maiores beneficiários dos recursos naturais são as empresas que os exploram e auferem altos lucros, deixando de legado cidades com pouca diversificação da atividade produtiva e regiões com sérios danos ambientais, exemplificado pelo rompimento de barragens de mineradoras despejando rejeitos de mineração no município de Mariana em 2015, e Brumadinho em 2019.

\subsection{Receitas Vinculadas de SUS e FUNDEB}

As receitas condicionadas de SUS e FUNDEB destinam recursos aos municípios com 0 intuito de cobrir os encargos de saúde e educação, respectivamente. Em relação ao SUS, observa-se um comportamento estável dos recursos, conforme o número de habitantes das cidades em questão nos dois estados, excetuando-se as capitais, onde os recursos são maiores devido aos serviços médicos mais complexos realizados na mesma e que absorvem a demanda de todo o estado. Já nos recursos do FUNDEB, nota-se um papel redistributivo nos montantes dos mesmos, apresentando uma tendência decrescente em relação ao tamanho dos municípios.

Trindade e Oliveira (2013) colocam que as transferências vinculadas são os melhores mecanismos de redistribuição na promoção de serviços como saúde e educação nos municípios do Pará, com o FUNDEB tendo maiores ganhos redistributivos, tais dados disponíveis nas figuras 9 e 10 corroboram para tal afirmativa ao se constatar que a partilha do FUNDEB proporciona uma maior descentralização das receitas do que o SUS e as demais transferências.

Figura 9 - Receita per capita do SUS e FUNDEB dos municípios do Pará por faixas de habitantes $2017-\mathrm{R} \$$

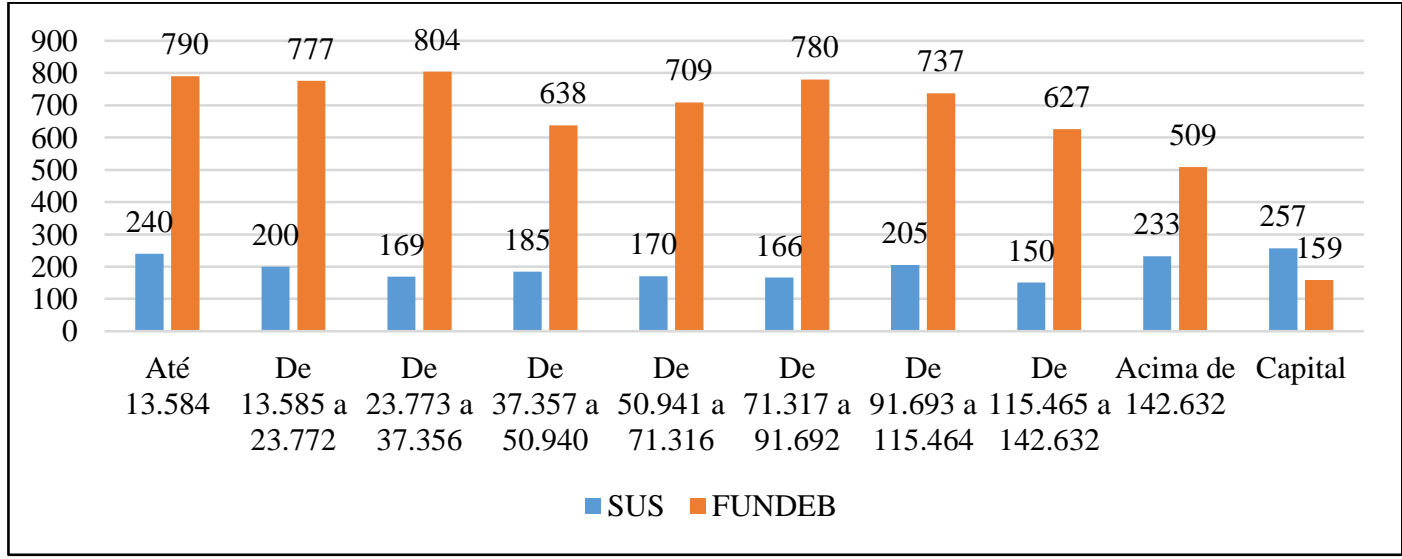

Fonte: Finanças do Brasil - FINBRA. STN - Ministério da Fazenda, 2018. Elaboração Própria. 
Figura 10 - Receita per capita do SUS e FUNDEB dos municípios de Minas Gerais por faixas de habitantes - $2017-\mathrm{R} \$$

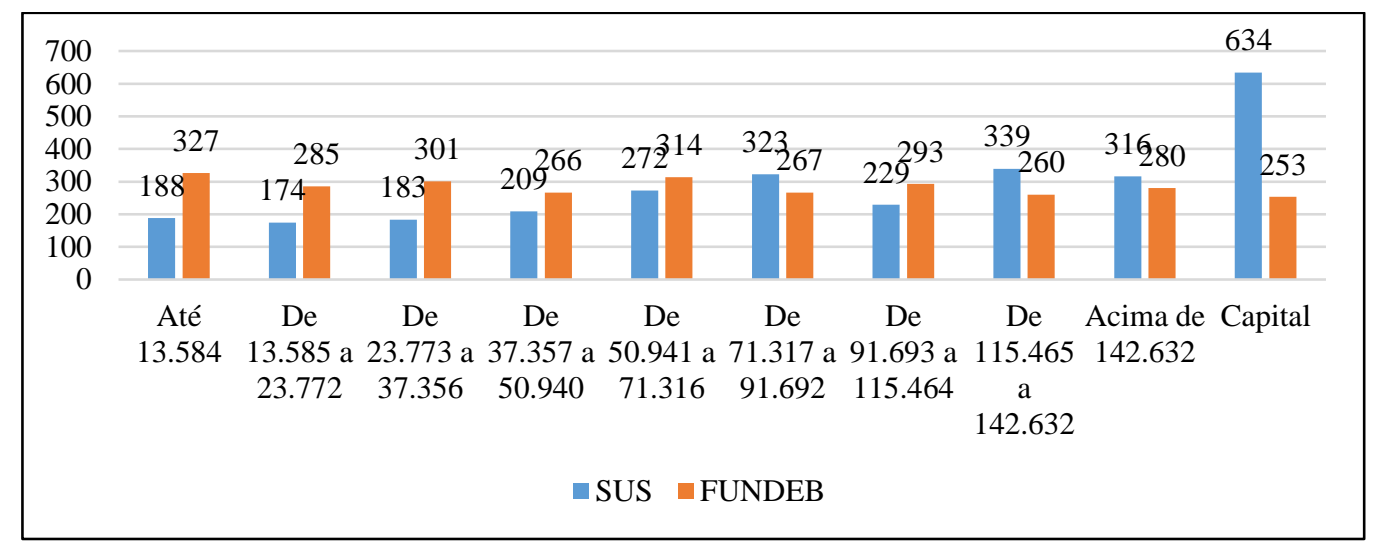

Fonte: Finanças do Brasil - FINBRA. STN - Ministério da Fazenda, 2018. Elaboração Própria.

\subsection{Comparação das Receitas Correntes sem FPM}

Quando comparadas as receitas per capita dos municípios pelas faixas de população sem o FPM, identifica-se que os municípios paraenses possuem melhores condições do que os mineiros nas duas primeiras faixas e na sétima, e nas demais faixas há uma posição melhor dos municípios mineiros, principalmente em relação às capitais, com Belo Horizonte apresentando mais que o dobro da receita per capita sem FPM em relação a Belém (Figura 11).

Figura 11 - Receitas per capita sem FPM dos municípios de Pará e Minas Gerais por faixas de habitantes - 2017 - R \$

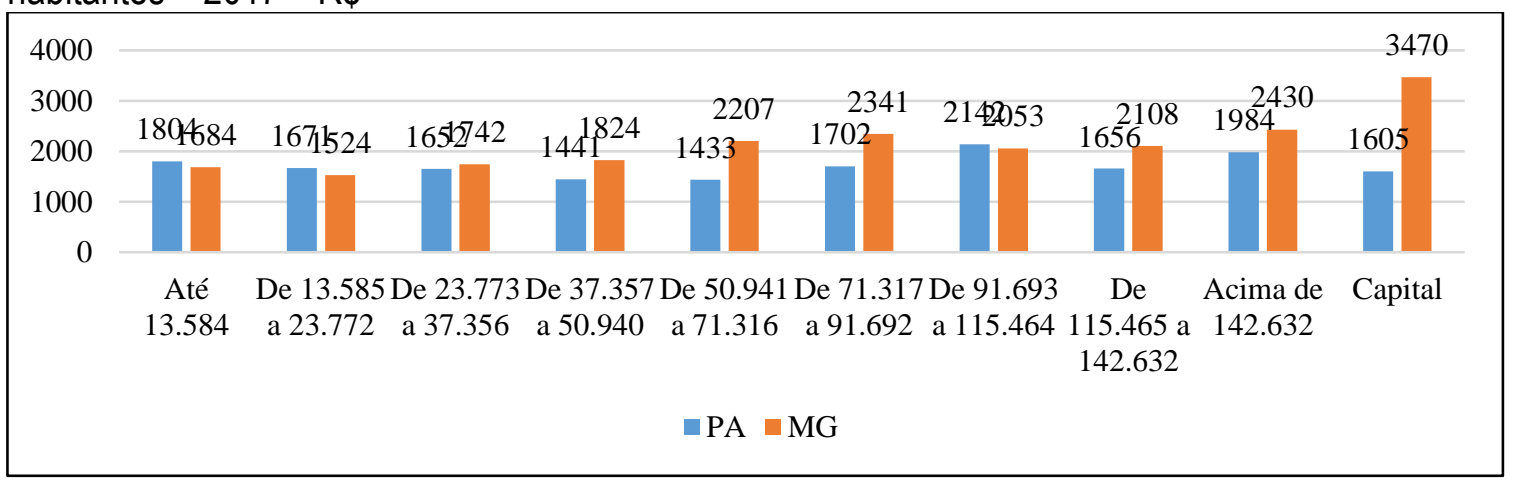

Fonte: Finanças do Brasil - FINBRA. STN - Ministério da Fazenda, 2018. Elaboração Própria.

Contudo, quando analisamos tais receitas por suas fontes (Figuras 12 e 13), identificamos que a situação mais favorável dos municípios paraenses advém dos recursos do FUNDEB e SUS, sendo o primeiro sua principal fonte de receita, sem levar em conta o FPM. Já em relação aos municípios mineiros, a maior participação de suas receitas tem sua origem na cota-parte do ICMS e na receita tributária, recurso este não vinculado a certos setores. Desta forma, entende-se que os municípios de Minas Gerais, ao possuírem um maior número de recursos não condicionados, possuem uma maior capacidade de gestão e interferência nos 
investimentos de infraestrutura urbana e no fortalecimento de arranjos produtivos locais que induzem a uma maior dinamicidade da economia local.

Figura 12 - Receitas per capita sem FPM dos municípios de Pará por fontes de receita e faixas de habitantes - $2017-\mathrm{R} \$$

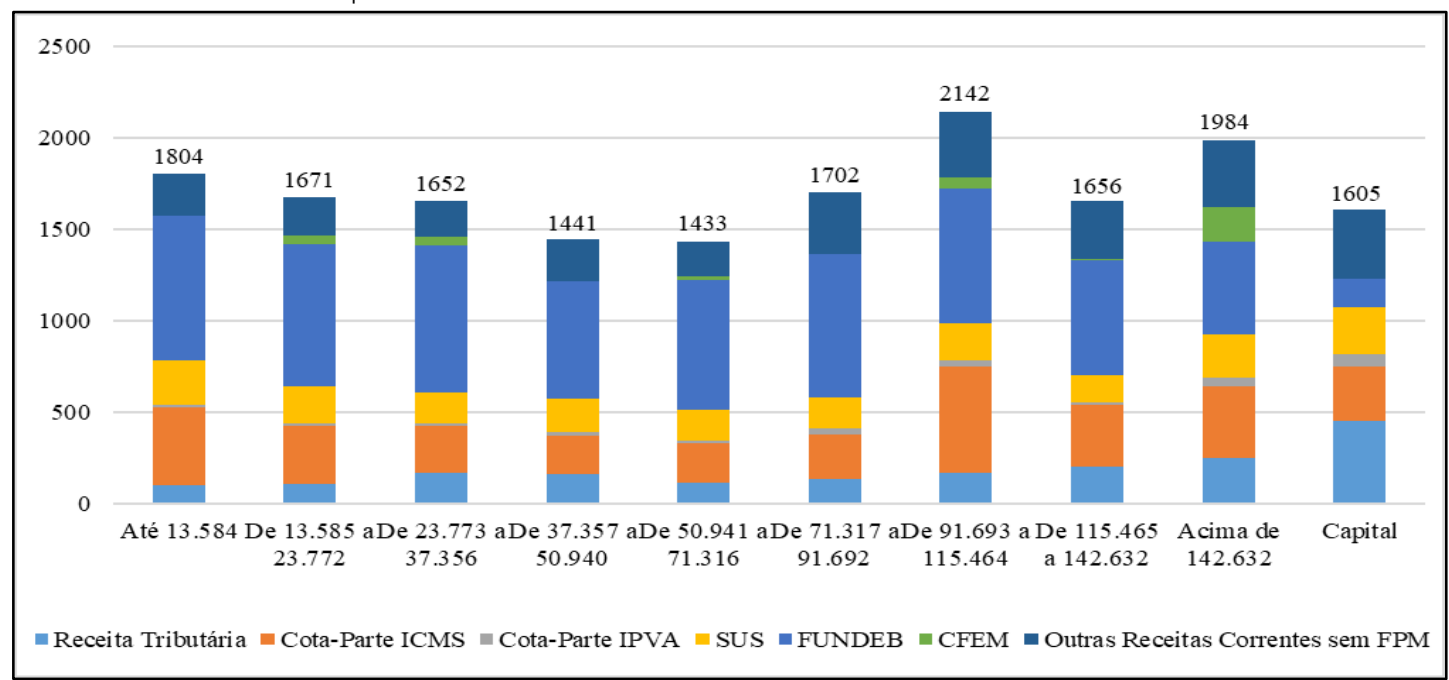

Fonte: Finanças do Brasil - FINBRA. STN - Ministério da Fazenda, 2018. Elaboração Própria.

Figura 13 - Receitas per capita sem FPM dos municípios de Minas Gerais por fontes de receita e faixas de habitantes - $2017-\mathrm{R} \$$

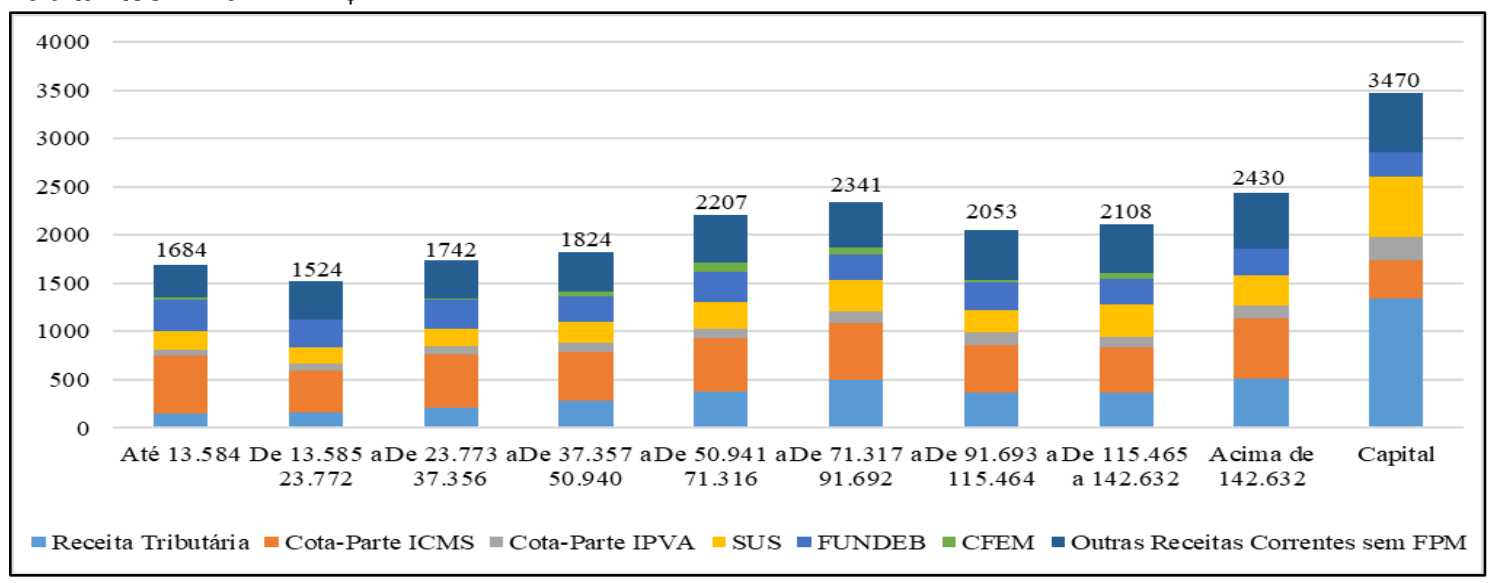

Fonte: Finanças do Brasil - FINBRA. STN - Ministério da Fazenda, 2018. Elaboração Própria.

\subsection{FPM e seus efeitos nas receitas per capita municipais de Pará e Minas Gerais em 2017}

A partir da análise anterior, é de se esperar que os recursos do fundo de participação deem conta de corrigir tais distorções dentro de cada estado, além de buscar uma equalização das receitas per capita de todos os municípios do Brasil. Dessa forma, verificar-se-á se tal equalização é atingida nas cidades dos estados de Pará e Minas Gerais, bem como, comparando se a equidade também é proporcionada confrontando os municípios de porte semelhantes das duas unidades federativas. 
Identifica-se, evidentemente, que os recursos do FPM per capita no Pará se comportam de forma decrescente ao elevar-se o número de residentes dos municípios. Dessa forma, há ganhos maiores aos municípios de menor população, como observado aos municípios da primeira faixa populacional possuírem receita per capita superior as demais faixas. Contudo, como visto, há algumas distorções nas receitas per capita sem o FPM muito relacionadas à atividade mineradora, assim, o tamanho populacional não é um indicador exato do nível de atividade econômica e geração de receitas do município (Figura 14).

Isso leva municípios como Canaã dos Carajás a receber $\mathrm{R} \$ 502,63$ de FPM per capita, e Marituba, município da região metropolitana de Belém, receber apenas $\mathrm{R} \$ 296,77$. O primeiro município possui menor número de habitantes, mas já é beneficiado pela atividade mineradora em seu território e sua receita per capita final chega a $R \$ 7.647,13$. Já o segundo é um município da região metropolitana de Belém, de baixa capacidade produtiva e de geração de receitas, sua receita per capita final chega apenas a $\mathrm{R} \$ 2.258,03$. Ou seja, Marituba recebe um valor abaixo de FPM per capita que Canaã dos Carajás, mesmo possuindo maiores necessidades de complementação das receitas próprias que o outro município.

Figura 14 -Receitas correntes per capita do FPM e sem FPM dos municípios do Pará por faixas de habitantes - $2017-\mathrm{R} \$$

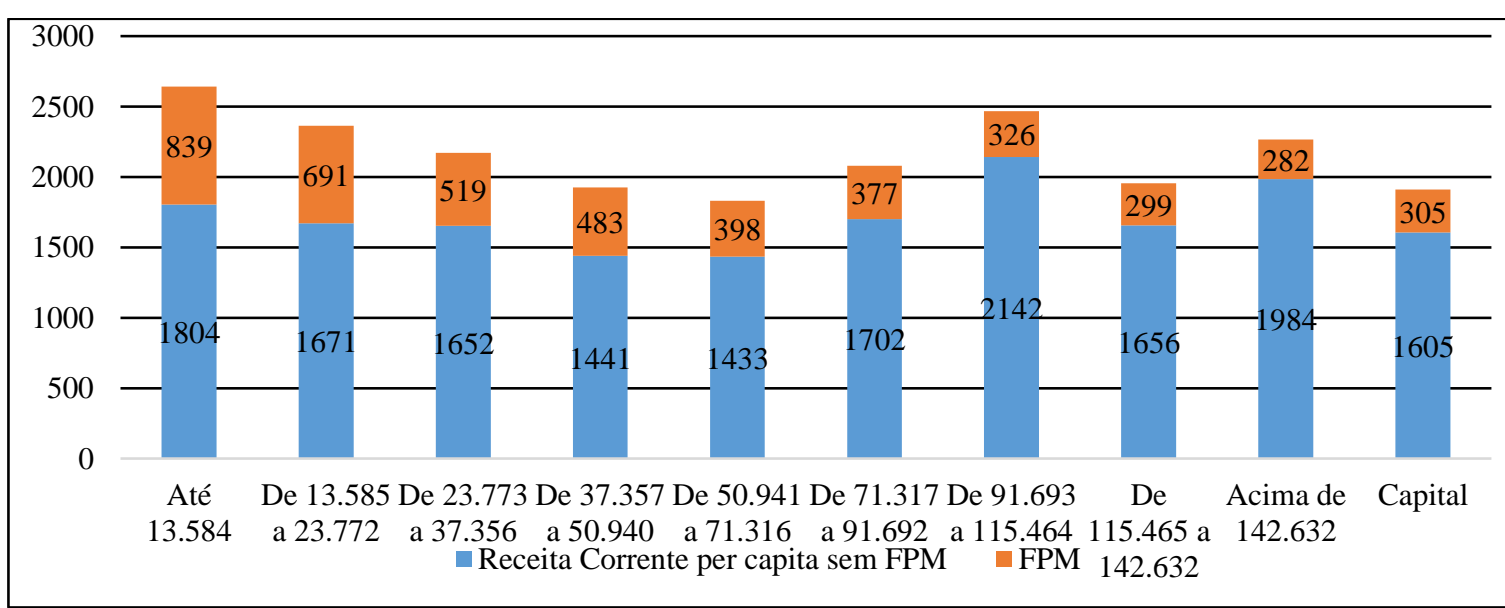

Fonte: Finanças do Brasil - FINBRA. STN - Ministério da Fazenda, 2018. Elaboração Própria.

Em Minas Gerais, os efeitos do FPM levam a uma maior receita per capita da primeira faixa populacional em relação às demais, excetuando-se a de Belo Horizonte. Em tal estado, as discrepâncias geradas pelo FPM consistem principalmente a respeita da primeira faixa graças ao grande número de municípios pequenos e nas faixas 5 e 6 onde estão em maior número os municípios mineradores (Figura 15). Em contrapartida, no Pará, como as desigualdades entre as cidades são maiores, os recursos do FPM têm efeito redistributivo marginal maior nas cidades menores que mais necessitam de recursos de complementação. 
Assim, a faixa de municípios mais penalizada dentro do estado de Minas Gerais são os municípios entre 13.585 a 23.772 habitantes que acabam com a menor receita per capita final, e a primeira se caracteriza como a mais beneficiada com os recursos do FPM elevando sua receita corrente per capita em $80,7 \%$.

Figura 15 - Receitas correntes per capita do FPM e sem FPM dos municípios de Minas Gerais por faixas de habitantes $-2017-\mathrm{R} \$$

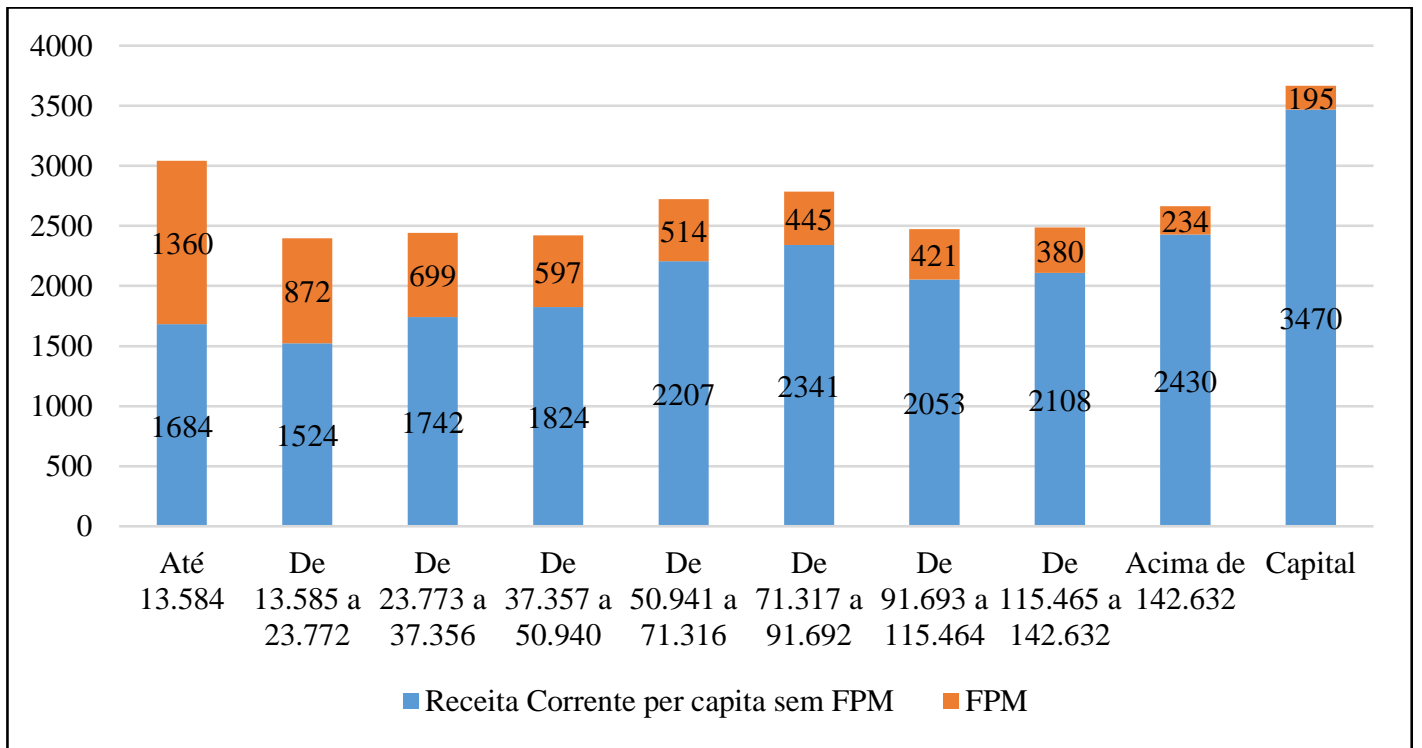

Fonte: Finanças do Brasil - FINBRA. STN - Ministério da Fazenda, 2018. Elaboração Própria.

Tais dados corroboram o levantado por Prado (2006b) em que coloca que os grandes prejudicados por tais critérios utilizados na partilha de FPM são as cidades dormitórios, que se localizam em volta de grandes centros urbanos como as capitais. Estes possuem pouca quantidade de geração de receitas próprias por suas pequenas bases tributáveis e também são penalizadas pelos critérios exógenos ao sistema tributário utilizado pelo FPM.

Bem como comprova, também, a tese da criação dos miniparaísos fiscais nos menores municípios, muito em função do coeficiente mínimo ser correspondente a municípios até 10.188 habitantes. Tal fenômeno é mais presente no estado de Minas Gerais pelo grande número de pequenos municípios, exemplificado por Serra da Saudade, o município com o menor número de habitantes dentre os estudados, possuir uma das maiores receitas correntes per capita.

\subsection{Comparação dos resultados entre os estados de Pará e Minas Gerais}

Comparando-se as receitas per capita dos estados de Pará e Minas Gerais no ano de 2017, constata-se que, diferentemente das receitas sem FPM, os municípios paraenses apresentam receitas maiores em nenhuma das faixas populacionais, diferentemente das três faixas que apresentava anteriormente (Figura 16). 
Figura 16 - Receitas correntes per capita dos municípios de Pará e Minas Gerais por faixas de habitantes - $2017-\mathrm{R} \$$

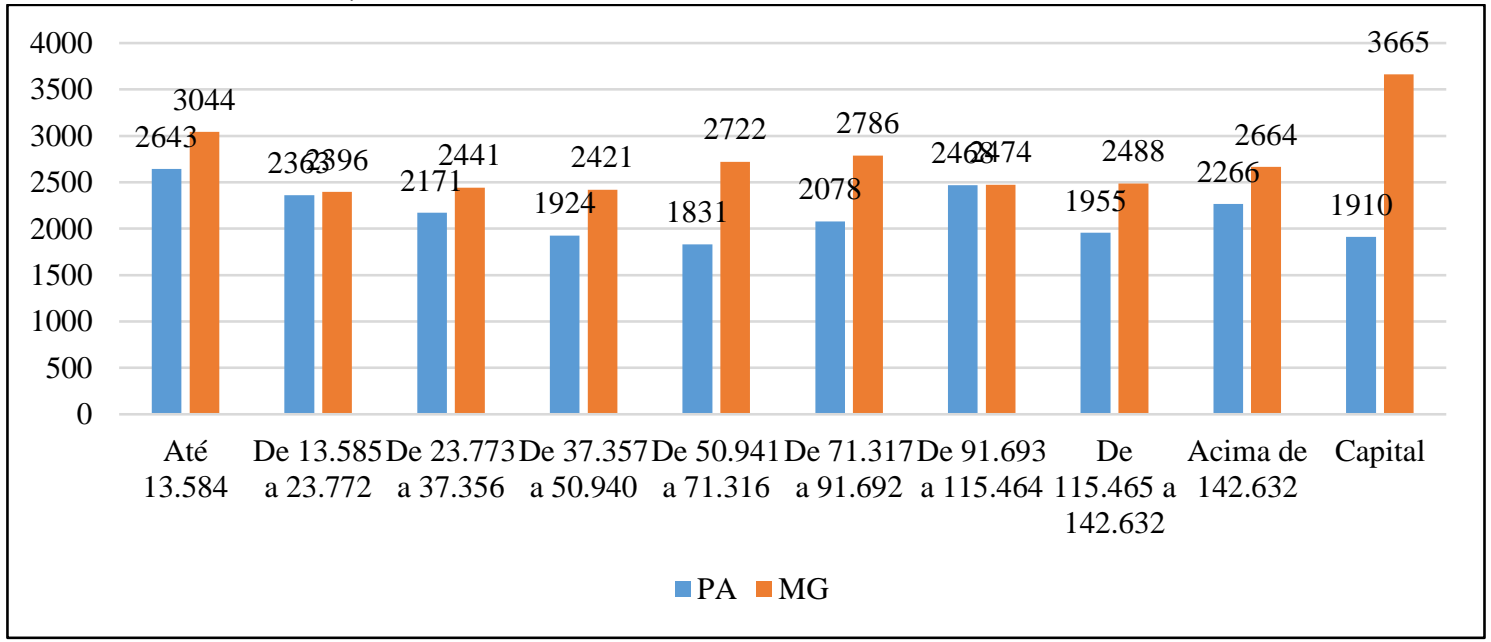

Fonte: Finanças do Brasil - FINBRA. STN - Ministério da Fazenda, 2018. Elaboração Própria.

Tal componente é visualizado de melhor forma quando comparadas às variações nas receitas per capita por faixas de municípios dos dois estados. As variações, nas três primeiras faixas de municípios, são muito maiores no estado de Minas Gerais quando comparadas às variações do estado do Pará, com a situação se invertendo nas faixas seguintes pelo fato dos municípios mineiros maiores já possuírem elevada receita per capita e seus ganhos marginais evidentemente serem menores.

Além disso, quanto ao aumento das receitas correntes per capita, quando considerado 0 total dos dois estados, há uma elevação maior do estado de Minas Gerais, um aumento de $27,3 \%$ contra um aumento do Pará de apenas $22,9 \%$. Ou seja, não se identifica o FPM como componente de equalização de gastos entre os estados das macrorregiões do Brasil e de mitigação das desigualdades regionais.

Outro fato a ser considerado, é a porcentagem da população nas faixas de habitantes mais prejudicadas dos dois estados. $54,69 \%$ da população do Pará encontra-se nas 5 faixas populacionais de pior receita per capita final do estado, enquanto apenas $35,17 \%$ dos residentes de Minas Gerais encontram-se nas cinco faixas de pior resultado per capita do seu estado. Lembrando ainda que as cinco piores faixas de Minas Gerais se apresentam em condições muito mais favoráveis do que as cinco faixas de população de menor receita per capita do Pará (Tabela 7).

Dessa forma, entende-se que o grau de injustiça fiscal é maior nos municípios do estado do Pará em relação às cidades mineiras, e que o fundo prevalece justamente as cidades do Sudeste, por lá se encontrarem um número maior de pequenos municípios (os maiores privilegiados com a repartição do fundo) e, consequentemente, a soma da população de cidades desse porte serem maiores percentualmente ao total de habitantes do estado. Como visto na 
tabela 4 , os residentes, nas cidades até 13.584 habitantes, representam apenas 1,99\% da população do Pará estudada neste trabalho, e tal porcentagem se eleva para 17,48\% em relação ao estado de Minas Gerais.

Em relação à média das receitas correntes per capita dos municípios dos dois estados, 0 Pará, possui média de $\mathrm{R} \$ 2.212,89,70,2 \%$ da média dos municípios do estado mineiro, de $\mathrm{R} \$$ $3.150,60$.

Tabela 7 - Receita corrente per capita sem FPM e com FPM e sua variação nos municípios de Pará e Minas Gerais por faixas de habitantes e total do estado - 2017

\begin{tabular}{lrrrrrr}
\hline & \multicolumn{3}{c}{ PA } & \multicolumn{3}{c}{ MG } \\
\cline { 2 - 8 } Faixa Populacional & $\begin{array}{c}\text { Receita Cor. per } \\
\text { capita sem FPM }\end{array}$ & $\begin{array}{c}\text { Rec. Corrente } \\
\text { per capita } \\
\text { Final }\end{array}$ & $\begin{array}{c}\text { Variação } \\
(\%)\end{array}$ & $\begin{array}{c}\text { Receita Cor. } \\
\text { per capita } \\
\text { sem FPM }\end{array}$ & $\begin{array}{c}\text { Rec. } \\
\text { Corrente per } \\
\text { capita Final }\end{array}$ & $\begin{array}{c}\text { Variação } \\
(\%)\end{array}$ \\
\hline Até 13.584 & 1804 & 2643 & 46,5 & 1684 & 3044 & 80,7 \\
\hline De 13.585 a 23.772 & 1671 & 2363 & 41,3 & 1524 & 2396 & 57,2 \\
\hline De 23.773 a 37.356 & 1652 & 2171 & 31,4 & 1742 & 2441 & 40,1 \\
\hline De 37.357 a 50.940 & 1441 & 1924 & 33,5 & 1824 & 2421 & 32,7 \\
\hline De 50.941 a 71.316 & 1433 & 1831 & 27,7 & 2207 & 2722 & 23,3 \\
\hline De 71.317 a 91.692 & 1702 & 2078 & 22,1 & 2341 & 2786 & 19,0 \\
\hline De 91.693 a 115.464 & 2142 & 2468 & 15,2 & 2053 & 2474 & 20,5 \\
\hline De 115.465 a 142.632 & 1656 & 1955 & 18,1 & 2108 & 2488 & 18,0 \\
\hline Acima de 142.632 & 1984 & 2266 & 14,2 & 2430 & 2664 & 9,6 \\
\hline Capital & 1605 & 1910 & 19,0 & 3470 & 3665 & 5,6 \\
\hline Total & 1693 & 2081 & 22,9 & 2184 & 2780 & 27,3 \\
\hline
\end{tabular}

Fonte: Finanças do Brasil - FINBRA. STN - Ministério da Fazenda, 2018. Elaboração Própria.

Tal situação se agrava ainda mais quando comparadas as receitas livres sem FPM, ou seja, aquelas que não possuem vinculação a qualquer gasto específico. Tais receitas são as que mais colaboram nos investimentos em infraestrutura que possam garantir o desenvolvimento dos municípios e uma maior diversificação de sua atividade produtiva com o intuito de aumentar a geração de receitas próprias dos mesmos, deixando-os menos dependentes de transferências intergovernamentais.

Quando se compara tais receitas sem vinculação, nota-se que, em todas as faixas populacionais, os municípios do Pará estão em piores condições do que os municípios mineiros. Mesmo assim, os incrementos per capita do FPM nos estados de Minas Gerais são maiores também em quase todas as faixas de municípios, excetuando-se apenas as duas últimas. Assim, garantindo a manutenção do status quo, com o fundo pouco contribuindo para que municípios de mesmo porte de estados menos favorecidos convirjam no sentido de igualar-se em condições de desenvolvimento com cidades do Sul e Sudeste do Brasil (Tabela 8). 
Tabela 8 - Receitas Livres ${ }^{1}$ per capita sem FPM e com FPM dos municípios de Pará e Minas Gerais por faixas de habitantes - $2017-\mathrm{R} \$$

\begin{tabular}{lllllll}
\hline Faixas de Habitantes & \multicolumn{3}{c}{ PA } & \multicolumn{2}{c}{ MG } \\
\cline { 2 - 7 } & $\begin{array}{l}\text { Receitas } \\
\text { Livres sem } \\
\text { FPM }\end{array}$ & FPM & $\begin{array}{c}\text { Receitas } \\
\text { Livres }\end{array}$ & $\begin{array}{c}\text { Receitas } \\
\text { Livres sem } \\
\text { FPM }\end{array}$ & FPM & $\begin{array}{c}\text { Receitas } \\
\text { Livres }\end{array}$ \\
\hline Até 13.584 & 605 & 839 & 1444 & 987 & 1360 & 2346 \\
\hline De 13.585 a 23.772 & 551 & 691 & 1242 & 885 & 872 & 1757 \\
\hline De 23.773 a 37.356 & 544 & 519 & 1063 & 1046 & 699 & 1745 \\
\hline De 37.357 a 50.940 & 464 & 483 & 948 & 1141 & 597 & 1738 \\
\hline De 50.941 a 71.316 & 414 & 398 & 812 & 1363 & 514 & 1878 \\
\hline De 71.317 a 91.692 & 573 & 377 & 950 & 1504 & 445 & 1948 \\
\hline De 91.693 a 115.464 & 1043 & 326 & 1369 & 1278 & 421 & 1699 \\
\hline De 115.465 a 142.632 & 772 & 299 & 1071 & 1282 & 380 & 1662 \\
\hline Acima de 142.632 & 1033 & 282 & 1316 & 1561 & 234 & 1795 \\
\hline Capital & 915 & 305 & 1221 & 2215 & 195 & 2410 \\
\hline
\end{tabular}

Fonte: Finanças do Brasil - FINBRA. STN - Ministério da Fazenda, 2018. Elaboração Própria. Nota:

${ }_{1}^{1}$ Para os cálculos das receitas livres foram excluídas as receitas das seguintes rubricas orçamentárias: Taxas, Contribuições, SUS, FNAS, FNDE, Transf. do estado para programas de saúde, FUNDEB e Convênios.

\subsection{FPM e a equalização de recursos entre os municípios brasileiros}

O FPM é um mecanismo redistributivo que gera diversas discussões acerca de suas funcionalidades, critérios e eficiências. Há diversos questionamentos quanto aos perfis de municípios que devem ser mais beneficiados e sobre a eficácia de uso de tal fundo como redutor de desigualdades entre as regiões do país. Mendes (2008) coloca que os estados mais ricos são os maiores prejudicados pelo fundo, pois eles são os maiores perdedores líquidos (o autor entende como financiamento líquido o quanto cada estado contribui com os impostos de IR e IPI menos o que estes recebem do FPM) e os estados das regiões Norte e Nordeste os maiores beneficiários.

Contudo, há de se salientar que o FPM, por ser um fundo com o objetivo de redistribuição, deve ser usado com o objetivo de combater as diferentes capacidades de financiamento dos municípios, e a adoção de análises de financiamento líquido não se justifica por esta não ser uma transferência devolutiva. Ou seja, o fundo busca corrigir desigualdades geradas ao longo de anos de investimentos concentrados nas regiões Sudeste e Sul do Brasil, que propiciaram que hoje em dia municípios das regiões em questão possam gerar maiores receitas.

Outro ponto levantado por Mendes (2008) diz respeito aos investimentos em infraestrutura que deveriam ser realizados pela esfera estadual e não municipal, e que as transferências destinadas a desenvolvimento de políticas sociais devem ser condicionadas e não livres, assim não justificando o uso das transferências livres advindas do FPM, com os 
programas de transferência de renda já cumprindo tal papel. Além disso, o autor coloca que a questão regional deve ser deixada de lado para focar-se na redução do hiato fiscal, ou seja, diferença entre a capacidade fiscal e a demanda por bens e serviços, argumentando que cidades grandes podem ter um elevado hiato fiscal, e cidades pequenas um hiato diminuto.

Entende-se que, de fato, é necessário focar na diminuição do hiato fiscal, contudo a demanda de bens e serviços e de custos díspares entre os municípios brasileiros é de difícil mensuração, principalmente por se tratar de um país subdesenvolvido de grande extensão territorial e população dispersa. Um dos indicadores mais aproximados de demanda de bens e serviços é a análise per capita, utilizada neste trabalho e, como observado na análise dos dados de Pará e Minas Gerais, a questão regional ainda é um problema nos critérios atuais de distribuição dos montantes, e deve ser levada em conta. Além de que, provavelmente, os custos de provisão de serviços básicos nas regiões Norte e Nordeste são maiores que nas demais, por estas estarem longe dos centros de produção de materiais e por sua população estar mais dispersa dentro dos estados.

Já em relação ao argumento que os investimentos em infraestrutura devem ser feitos a nível estadual e não local, há de se considerar que há a necessidade de municípios possuírem certo orçamento livre. A administração local deve exercer seu papel de gestor público, detectando os gargalos em suas jurisdições, permitida pela maior proximidade da esfera de poder com a população, e buscando superá-los com investimentos que incentivem as produções locais e a capacitação de trabalhadores, aumentando a base tributária e a arrecadação própria da cidade (OATES, 1999). Evidentemente, os recursos condicionados a setores de saúde e educação, bem como as transferências de programas sociais são muito importantes nas reduções das desigualdades, porém é necessário investimento em infraestrutura para que se possa buscar a convergência do desenvolvimento em todos os municípios brasileiros.

Politi e Mattos (2014) ainda acrescenta como questionamento o paradoxo de ser considerado pouco eficiente o direcionamento de grande volume de recursos a cidades com poucas demandas de serviços públicos e ao mesmo tempo, caso sejam priorizados os municípios de maior população há grandes efeitos no sentido de aumentar os congestionamentos e a concentração populacional nos mesmos municípios.

Assim, como observado por Prado (2006b), entende-se que o Brasil não possui qualquer sistema de equalização que tenha por intuito igualar as receitas per capita de seus municípios, mas sim apenas fluxos redistributivos, utilizando critérios exógenos sem levar em conta as demais fontes de receitas dos municípios. Nesse sentido, tais recursos dos fundos apresentam maior nível de equalização em certos estados e menores em outros, onde discrepâncias existem 
graças a inexistência da relação diretamente proporcional perfeita em que considera que ao elevar-se o número de habitantes eleva-se também o seu nível de desenvolvimento e bases tributárias.

Nos dois estados estudados, Pará e Minas Gerais, as discrepâncias das contas municipais se relacionam, evidentemente com a capacidade fiscal e tamanho dos municípios, mas em especial pela existência de municípios mineradores, em que apresentam receita per capita final acima que as demais cidades de mesmo porte. No caso do Pará, as cidades mais prejudicadas são as de faixa populacional 4, 5, 6, 8 e 10 e as de Minas Gerais são as 2, 3, 4, 7 e 8. Assim como em outros estados tais distorções devem se relacionar as suas próprias especificidades de distribuição de capacidade produtiva dentro de seus territórios.

Dessa forma, entende-se que os critérios entre os municípios do mesmo estado deveriam contar com a participação dos governos estaduais. Estes por estarem mais próximos das realidades das suas cidades, poderiam proporcionar uma divisão mais justa dos recursos, 0 que um critério nacional aplicado em 5.570 municípios nunca conseguirá alcançar pelas mais variadas especificidades existentes.

\section{CONSIDERAÇÕES FINAIS}

O federalismo brasileiro, assim como em outros países, experimentou ondas de descentralização e centralização ao longo de sua história. Contudo, é necessário salientar que o seu processo de desconcentração dos encargos e das receitas tributárias advindas com a constituição de 1988 ocorreu por motivações e pressões políticas dos entes subnacionais que demandavam por maiores participações no bolo tributário. Tal fato, ao não levar em consideração a eficiência no processo de descentralização, gerou grande parte dos problemas referentes aos mecanismos redistributivos.

A União, ao ter grande parte de suas receitas compartilhadas de seus principais impostos com os entes subnacionais, concentra seus esforços na arrecadação de contribuições sociais, diminuindo, assim, o esforço fiscal e as participações dos impostos divididos com estados e municípios, o que compromete os aportes dos fundos de participação de estados e municípios (REZENDE et al, 2007). Como resposta a pressões dos entes subnacionais, principalmente aos dos municípios, o Governo Federal as atende com elevações do percentual referente ao FPM com emendas constitucionais, postergando uma revisão de critérios, que tem como base parâmetros criados na reforma tributária de 1966, os quais não representam mais a realidade atual. 
Tais critérios ficaram ainda mais prejudicados com os congelamentos das fatias referentes aos estados e municípios de seus fundos de participação no início dos anos 1990, que levaram os mecanismos redistributivos brasileiros a não considerarem as dinâmicas econômicas, sobrevalorizando os estados que antes eram territórios federais em relação ao FPE, e na utilização de um parâmetro que não leva em consideração as demais formas de financiamentos dos municípios em relação ao FPM.

Segundo Prado (2016) o objetivo ideal consiste em todo governo regional ou municipal ter aproximadamente a mesma capacidade de gasto per capita. Shah (1994) coloca que sistemas de equalização para atingirem seus critérios de eficiência e equidade deve considerar os gastos públicos, e que o sistema de equalização mais recomendável seria através de autofinanciamento dos próprios governos subnacionais que decidiriam suas partes correspondentes através de negociações, com o governo central apenas complementando quando necessário.

Como exemplo de situações em que tais critérios atuam, Prado (2016) coloca que, na Alemanha, ocorre transferências horizontais, onde os länder (ente subnacional análogo aos estados brasileiros) mais ricos transferem recursos aos mais pobres, atingindo um elevado nível de equalização, com o länder mais rico possuindo receita per capita apenas 106\% em comparação à média, e o mais pobre com 95\% em relação a mesma média. É evidente que não se pode esperar níveis aproximados aos alcançados no modelo alemão, pois se trata de um país desenvolvido e com capacidades fiscais muito menos desiguais do que as do Brasil, ou seja, os mecanismos redistributivos lá tratam de corrigir diferenças muito menores.

Contudo, como Prado (2006a) ressalta, o nível de equidade de um país depende de quanta importância o mesmo dá à questão. Em relação ao Brasil, identifica-se a falta de visibilidade do debate nos meios de comunicação e a carência de instituições governamentais permanentes que viabilizem a discussão entre representantes dos entes subnacionais e que façam uma mensuração dos custos, do potencial fiscal de cada ente subnacional e encargos díspares dentro do território nacional. (PRADO, 2016). Os argumentos colocados demonstram a urgente necessidade de uma reforma tributária estrutural no Brasil, em especial em relação aos fundos de participação. Mudanças pontuais, como desvinculação de receitas ou aumento de participação na arrecadação dos impostos financiadores dos fundos não irão resolver 0 problema, caso não se faça uma revisão nos critérios de distribuição incorporando as outras fontes de financiamentos dos municípios no cálculo dos montantes, e internalizando as mudanças ao longo do tempo. 
Em relação ao FPM, objeto deste trabalho, identificou-se que as principais distorções acerca de municípios de mesmo porte, de Pará e Minas Gerais, que apresentavam receitas per capita muito díspares se deu pela existência dos municípios mineradores. Assim como em outros estados poderá haver distorções em relação a outros fatores, como no Rio de Janeiro e os municípios que recebem royalties do petróleo. Em momento algum, considera-se que tais especificidades de municípios sejam ruins, o que se levanta é a questão da necessidade dos mecanismos redistributivos se adaptarem a estas diferentes capacidades de financiamento dos municípios brasileiros a fim de se aproximarem cada vez mais de um sistema de equalização.

Assim, identifica-se que a distribuição dos recursos dentro de cada estado poderia ser instituída por lei estadual. Os estados, com uma maior aproximação aos seus municípios, poderiam criar critérios muito mais justos do que uma regra única para o país inteiro e mais de cinco mil municípios. Além disso, aumentaria o poder de coordenação dos estados de políticas de desenvolvimento regional, fragilizada pela peculiaridade brasileira dos municípios serem considerados entes subnacionais em pé de igualdade com os estados e negociando recursos diretamente com a União.

Um bom exemplo de lei estadual, refere-se a já citada Lei Robin Hood de Minas Gerais, que, segundo Riani (2014), representou um importante papel desconcentrador de receitas da cota-parte do ICMS no estado. Tais critérios dentro de cada estado, junto com um maior peso as regiões menos desenvolvidas do montante total dos fundos já representariam importantes avanços na busca por uma maior equalização das receitas per capita dos municípios.

Ao abordar tal tema, espera-se promover ainda mais o debate acadêmico acerca das questões redistributivas, além de propor trabalhos que complementem a este com o estudo pelo lado do gasto público, e na identificação das demandas sociais inerentes a pequenas e grandes cidades, podendo assim descobrir se as diferentes receitas per capita possuem correlação com os indicadores sociais e econômicos de tais municípios. Afinal, a equalização de receitas de nada irá adiantar, caso as administrações municipais não identifiquem em suas jurisdições os setores carentes de investimento, a fim de superar gargalos de produção e induzir o aumento da arrecadação própria da cidade com a expansão de suas bases tributáveis.

\section{REFERÊNCIAS BIBLIOGRÁFICAS}

ANDERSON, George. Federalismo: uma introdução. Editora FGV, 2009.

BRASIL. EMENDA CONSTITUCIONAL N 55, DE 20 DE SETEMBRO DE 2007. Altera o art. 159 da Constituição Federal, aumentando a entrega de recursos pela União ao Fundo de Participação

dos Municípios.

Disponível em 
http://www.planalto.gov.br/ccivil_03/constituicao/emendas/emc/emc55.htm>. Acesso em 29 dez 2017.

EMENDA CONSTITUCIONAL No 84, DE 2014. Altera o art. 159 da Constituição Federal para aumentar a entrega de recursos pela União para o Fundo de Participação dos Municípios.

Disponível em http://www2.camara.leg.br/legin/fed/emecon/2014/emendaconstitucional-84-2-dezembro-2014779653-publicacaooriginal-145516-pl.html>. Acesso em 29 dez 2017.

CONFEDERAÇÃO NACIONAL DOS MUNICÍPIOS (CNM). Entenda a CFEM (Compensação Financeira pela Exploração de Recursos Minerais). Estudos Técnicos CNM - Volume 5, p. 179-188, Julho, 2012.

ENRIQUEZ, Maria Amélia Rodrigues da Silva. Royalties da mineração: instrumento de promoção do desenvolvimento sustentável de regiões mineradoras na Amazônia Oriental? 1998.

FUNDAÇÃO DE AMPARO A ESTUDOS E PESQUISAS DO PARÁ (FAPESPA). "O impacto da Lei Kandir na Arrecadação do ICMS dos Estados no período 1997 - 2016: Estimativas das perdas com as Desonerações das Exportações de Produtos Primários e Semielaborados" (Nota Técnica). Fundação de Amparo a Estudos e Pesquisas do Pará, Belém, 2017.

GUEDES, Kelly Pereira; GASPARINI, Carlos Eduardo. Descentralização fiscal e tamanho do governo no Brasil. Economia Aplicada, v. 11, n. 2, p. 303-323, 2007.

KHAIR, Amir. A questão fiscal e o papel do Estado. São Paulo: Editora Fundação Perseu Abramo, 2013.

MENDES, M.; MIRANDA, R. B.; COSIO, F. B. Transferências Intergovernamentais no Brasil: diagnóstico e proposta de reforma. Texto para Discussão $n^{0} 40$. Brasília: Consultoria Legislativa do Senado Federal, abr. 2008.

MINAS GERAIS. LEI N 18.030, DE 12 DE JANEIRO DE 2009. Dispõe sobre a distribuição da parcela da receita do produto da arrecadação do ICMS pertencente aos Municípios. Disponível em <https://www.almg.gov.br/consulte/legislacao/completa/completa-novamin.html?tipo=LEl\&num=18030\&comp=\&ano=2009\&texto=original>. Acesso em 29 dez 2017.

NUN, José. La desigualdad y los impuestos. Una introducción para no especialistas. Buenos Aires: Capital Intelectual, 2011. Tomo II.

OATES, Wallace E. An essay on fiscal federalism. Journal of economic literature, v. 37, n. 3, p. 1120-1149, 1999.

PARÁ. LEI No 6.276, DE 29 DE DEZEMBRO DE 1999. Altera dispositivos da Lei $\mathrm{n}^{\circ} \mathbf{5 . 6 4 5}$, de 11 de janeiro de 1991, que dispõe sobre critérios e prazos de créditos e repasse da cotaparte das parcelas do ICMS e outros tributos da arrecadação do Estado e por este recebidas, pertencentes aos Municípios, e dá outras providências. Disponível em < http://www.pge.pa.gov.br/sites/default/files/lo6276.pdf>. Acesso em 29 dez 2017.

POLITI, Ricardo Batista; MATTOS, Enlinson. Transferências intergovernamentais e equalização fiscal regional: evidências para municípios do Brasil. Anais do XLI Encontro Nacional de Economia. ANPEC-Associação Nacional dos Centros de Pós-graduação em Economia, 2014.

PRADO, Sérgio. "Federalismo no Brasil e Alemanha - comparações". In: CAMPOS, César; MENDES, Gilmar. Federalismo Fiscal Brasil-Alemanha. Volume 4, FGV projetos, p. 195-238, 2016.

"Transferências fiscais no Brasil: o lado "esquecido" da reforma tributária". In: PINTO, Márcio Percival Alves; BIASOTO JR, Geraldo (Orgs.), Política Fiscal e Desenvolvimento no Brasil. Campinas-SP. Editora da Unicamp, pp 173-236, 2006b.

Equalização e federalismo fiscal: uma análise comparada: Alemanha, Índia, Canadá, Austrália. Konrad-Adenauer-Stiftung, Cap. 1, p. 15-56, 2006a.

REZENDE, Fernando (2001). Finanças Públicas - $2^{\circ}$ edição- São Paulo; Atlas. 
REZENDE, Fernando; OLIVEIRA, Fabrício Augusto de; ARAÚJO, Erika. 0 dilema fiscal: remendar ou reformar? Rio de Janeiro. Editora FGV, 2007.

RIANI, Flávio. Impactos distributivos regionais da lei Robin Hood. Anais do XVI Seminário de Economia Mineira, Diamantina, 2014.

RIANI, Flávio; ALBUQUERQUE, Célio MP. A Lei Complementar 87/96 (Lei Kandir): balanço de perdas e ganhos e proposta de mudança-o caso de Minas Gerais. SEMINÁRIO SOBRE A ECONOMIA MINEIRA, v. 9, 2000.

STIGLITZ, J. E. La economia del sector público. Madri: Antoni Bocsh, 2000.

TRINDADE, J. R. B e OLIVEIRA, W. As finanças dos municípios paraenses: ensaio analítico sobre as receitas de transferências e de suas principais despesas sociais. REDES (Revista do desenvolvimento Regional) (Santa Cruz do Sul, RS), v. 18, n.2, p. 246-273, 2013. Disponível em: http://goo.gl/ru2Uwo.

TRINDADE, José Raimundo. "Mineração e políticas de desenvolvimento local para o município de Parauapebas no Pará". In: Francisco Rego Chaves, FERNANDES, ENRÍQUEZ, Maria Amélia Rodrigues da Silva; ALAMINO, Renata de Carvalho Jimenez (Eds.). Recursos Minerais \& Sustentabilidade Territorial: grandes minas. Rio de Janeiro: CETEM/MCTI, p. 19-38, 2011.

Recebido para avaliação em Outubro de 2019.

Aceito para publicação em Janeiro de 2020. 


\section{RESUMO}

Este trabalho tem por intuito investigar os critérios de repasse do Fundo de Participação dos Municípios - FPM e quais os níveis de equalização fiscal obtidos por estes comparando os impactos dos recursos do mesmo nos orçamentos dos municípios de Pará e Minas Gerais no ano de 2017. Entende-se que os critérios utilizados pelo fundo, principalmente populacionais, estão desatualizados e não levam em consideração as peculiaridades e demais formas de financiamento dos municípios, nos estados estudados muito em razão da existência da atividade mineradora, alcançando resultados insuficientes na equalização das receitas. Em relação ao FPM, objeto deste trabalho, identificou-se que as principais distorções acerca de municípios de mesmo porte, de Pará e Minas Gerais, que apresentavam receitas per capita muito díspares se deu pela existência dos municípios mineradores. Assim como em outros estados poderá haver distorções em relação a outros fatores, como no Rio de Janeiro e os municípios que recebem royalties do petróleo. Em momento algum, considera-se que tais especificidades de municípios sejam ruins, o que se levanta é a questão da necessidade dos mecanismos redistributivos se adaptarem a estas diferentes capacidades de financiamento dos municípios brasileiros a fim de se aproximarem cada vez mais de um sistema de equalização.

PALAVRAS-CHAVE: Federalismo Fiscal; Transferências Intergovernamentais; Equalização fiscal; FPM.

\section{ABSTRACT}

This work aims to investigate the criteria for transferring the Municipality Participation Fund - FPM and the levels of fiscal equalization obtained by them comparing the impacts of its resources on the budgets of the municipalities of Pará and Minas Gerais in the year 2017. Understands It is believed that the criteria used by the fund, mainly population, are out of date and do not take into account the peculiarities and other forms of financing of the municipalities, in the states studied, due to the existence of mining activity, achieving insufficient results in the equalization of revenues. In relation to the FPM, the object of this work, it was identified that the main distortions concerning municipalities of the same size, in Pará and Minas Gerais, which presented very different per capita revenues, occurred due to the existence of mining municipalities. As in other states, there may be distortions in relation to other factors, such as in Rio de Janeiro and the municipalities that receive oil royalties. At any time, it is considered that such specificities of municipalities are bad, what is raised is the question of the need for redistributive mechanisms to adapt to these different financing capacities of Brazilian municipalities in order to increasingly approach a system of equalization.

KEYWORDS: Fiscal Federalism; Intergovernmental Transfers; Fiscal equalization; FPM. 